\title{
In Vitro Investigations on Optimizing and Nebulization of IVT-mRNA Formulations for Potential Pulmonary based Alpha-1-Antitrypsin Deficiency Treatment
}

\section{Shan Guan}

Department of Microbiology and Biochemical Pharmacy, National Engineering Research Center of Immunological Products, Third Military Medical University, Chongqing

Max Darmstaedter

Ludwig-Maximilians-Universität München: Ludwig-Maximilians-Universitat Munchen

Chuanfei Xu

Department of Microbiology and Biochemical Pharmacy, National Engineering Research Center of Immunological Products, Third Military Medical University, Chongqing Joseph Rosenecker ( $\sim$ joseph.rosenecker@med.uni-muenchen.de) Ludwig-Maximilians-Universität München https://orcid.org/0000-0002-9613-5393

\section{Research}

Keywords: gene therapy, IVT-mRNA, alpha-1-antitrypsin deficiency, lipofectamine, nebulization

Posted Date: March 29th, 2021

DOI: https://doi.org/10.21203/rs.3.rs-133486/v2

License: (c) (1) This work is licensed under a Creative Commons Attribution 4.0 International License. Read Full License 


\section{Abstract}

Background: In vitro transcribed (IVT) mRNA has come into focus in recent years as a potential therapeutic approach for the treatment of genetic diseases. The pulmonary delivery of IVT-mRNA encoding alpha-1-antitrypsin (A1AT) is a promising strategy for protein replacement therapy of alpha-1antitrypsin deficiency (AATD). The nebulized A1AT-mRNA formulations would be a highly acceptable and tolerable remedy for the AATD patients in the future.

Method: we first optimized parameters that influencing the transfection efficiency of formulations containing IVT-mRNA and Lipofectamine2000 based on human bronchial epithelial cells transfection. Cell viability was evaluated by performing MTT assay after transfection with different IVT-mRNA lipoplexes. Functional analysis was employed to assess the biological function of A1AT proteins produced from optimized formulations using anti-trypsin assay and anti-elastase assay.

Results: Lipoplexes prepared by IVT-mRNA encoding A1AT (A1AT-mRNA) in optimum conditions could successfully transfect human bronchial epithelial cells without significant toxicity. A reduction in transfection efficiency was observed for aerosolized lipoplexes that can be partially overcome by increasing the initial amount of components. A1AT produced from cells transfected by nebulized A1ATmRNA lipoplexes is functional and could successfully inhibit the enzyme activity of trypsin as well as elastase.

Conclusion: Aerosolization of A1AT-mRNA therapeutic constitute a potentially powerful means to transfect airway epithelial cells with the purpose of producing functional A1AT while bringing along the unique advantages of IVT-mRNA.

\section{Background}

Nucleic acid based therapeutics encoding specific proteins of interest have shown great potential in the treatment of devastating diseases such as genetic disorders, infectious diseases, cancer and cardiovascular diseases [1-3].There are already several nucleic acid based drugs on the market and thousands of gene therapy approaches are tested in clinical trials worldwide [4]. In vitro transcribed messenger RNA (IVT-mRNA) has emerged as an alternative to the conventional DNA based therapeutic and provides many unique features to be a promising drug candidate, for example high efficiency in transfecting non-dividing cells and ease of production [5]. Most importantly, IVT-mRNA offers a huge advantage in terms of safety, it has no risk of insertional mutagenesis. IVT-mRNA is able to rapidly express the desired protein in the cytoplasm and automatically degrade afterwards, so the protein expression could be easily controlled [6, 7]. With an in-depth understanding of the IVT-mRNA structure and the utilization of modified nucleotides, the stability and expression efficiency of IVT-mRNA have been greatly improved [8]. In the last decade, IVT-mRNA has entered a golden period of development. A large number of IVT-mRNA based therapeutics is tested in clinical trials [9-15], and recently IVT-mRNA has showed great potency in developing efficacious vaccine approaches to eliminate the spread of severe 
acute respiratory syndrome coronavirus 2 (SARS-CoV-2), the causative culprit of coronavirus disease 2019 (COVID-19) [16, 17].

For preclinical and clinical applications different routes of delivery of IVT-mRNA complexes to the target tissue are being tested, such as intramuscular, intradermal, intranodal, subcutaneous, intravenous and intrathecal. However, an important but not well-investigated field is the pulmonary delivery of IVT-mRNA. The lung airway, with its large surface area, represents an attractive target for IVT-mRNA based gene therapy approaches designed to treat inherited monogenic diseases [18]. The local delivery of IVT-mRNA through the respiratory tract is a simple administration route that is deprived of drawbacks inherent to intravenous administration. The lung has a rich capillary network and strong angiogenic capacity, which can mediate secreted proteins into the circulatory system $[19,20]$. There are theoretically three options when selecting the most appropriate method for administering IVT-mRNA to the lung airway: nebulization of liquid-suspended IVT-mRNA complexes, inhalation of a dried formulation of the genetic payload with carrier particles or pressurized expulsion of IVT-mRNA from a propellant dispersion [21]. Of these methods, nebulization remains the most exploited one for introducing gene vectors into the lung both in animal and clinical studies. Indeed, nebulization is the only pulmonary delivery method that has been applied in the most recent cystic fibrosis gene therapy clinical trial [22], because the administration of drugs by inhalation of aerosols is a highly acceptable and tolerable administration route for the patient, and the nebulized formulation tends to be more evenly distributed throughout the respiratory tract [23]. However, nebulization of gene therapy formulations can be inefficient: shearing force, preferential nebulization of the solute and adhesion to plastic can mean that as little as $10 \%$ of nucleic acids payload in the nebulization chamber is successfully emitted through the mouthpiece [24]. These limitations will not only decrease the therapeutic potential of nebulized formulations, but also increase the cost of gene therapy products. Nevertheless, optimized formulations and advanced nebulization strategies have significantly improved the situation, it has been proved by recent studies that nebulization of IVT-mRNA complexes is feasible and could be successfully used for in vitro and in vivo applications $[25,26]$. As a result, nebulized IVT-mRNA formulations appears to be an attractive therapeutic approach for the treatment of a broad range of respiratory diseases. One of the most commonly quoted examples among which is alpha-1-antitrypsin deficiency [20].

Alpha-1-antitrypsin deficiency (AATD) is one of the most common hereditary disorders in Caucasians of European decent [27]. It is an autosomal recessive disorder caused by mutations within the SERPINA1 gene and characterized by low levels of alpha-1-antitrypsin (A1AT) in the serum $[28,29]$. A1AT is mainly synthesized and secreted by hepatocytes but its primary function is to inhibit activity of neutrophil elastase in the lung, a serine protease that is able to destroy alveoli and cleave components of the extracellular matrix [30]. The lower respiratory tract of AATD patients is not protected against the destructive influence of neutrophil elastase, so AATD patients have a high risk of developing emphysema and chronic obstructive pulmonary disease [31, 32]. Besides anti-protease properties, A1AT possesses multiple anti-inflammatory and tissue protective properties. A1AT is able to reduce neutrophil chemoattractants such as leukotriene $\mathrm{B} 4$, as well as proinflammatory cytokines such as tumor necrosis

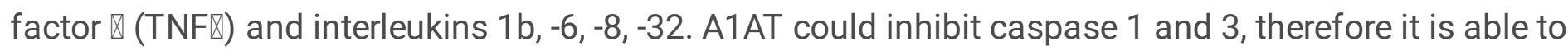


protect cells from apoptosis [33]. Apart from the constitutive tissue protector function, recent data indicate that A1AT is also an inhibitor of SARS-CoV-2 infection and two of the most important proteases in the pathophysiology of COVID-19: the transmembrane serine protease 2 (TMPRSS2) and the disintegrin and metalloproteinase17 (ADAM17) [34]. TMPRSS2 is essential for SARS-CoV-2-S protein priming and viral infection [35]. ADAM17 mediates ACE2 (angiotensin I converting enzyme II, the SARSCoV-2 entry receptor), IL-6R, and TNF-a shedding [34]. In addition, clinical findings indicate that lower A1AT levels are related to worse prognosis inCOVID-19 patients [36].

To date the only available treatment option for AATD is augmentation therapy being approved for selected patients with severe AATD related pulmonary emphysema [37]. Nevertheless, A1AT augmentation therapy is costly and requires frequent intravenous infusion of A1AT purified from pooled human plasma, which has the risk of viral contamination and allergic reactions [38]. On the other hand, IVT-mRNA based gene therapy could eliminate the burden of protein infusion and significantly reduce the costs and associated risks [39]. A previous study suggested that A1AT expression could be observed in the lung and liver of mice which intravenously be injected by a single dose of IVT-mRNA encoding A1AT (A1AT-mRNA) [40]. Because pathologies related to the deficiency of A1AT mainly concern the lung, aerosolized A1AT-mRNA could potentially be applicable for the treatment of AATD patients. However, to the best of our knowledge, there is no study published up to now explored the potential of nebulized IVTmRNA therapeutic for the treatment of AATD.

For delivery of IVT-mRNA based therapeutics to the patient by inhalation several challenges have to be addressed, one of the most important tasks would be protecting the vulnerable mRNA molecules against shear forces caused by nebulization. In this context, we carried out this proof-of-concept study aiming to investigate whether aerosolized IVT-mRNA-carrying formulations could successfully transfect airway epithelial cells and produce sufficient amounts of functional A1AT. In order to facilitate the efficient intracellular delivery of IVT-mRNA, Lipofectamine2000 was used as a transfection agent due to the fact that it has shown favorable results in the context of IVT-mRNA mediated in vitro transfection [25, 41]. An optimal way to prepare IVT-mRNA/Lipofectamine2000 lipoplexes, which guarantee efficient transfection with minimum cytotoxicity, was evaluated in the first part of current study. After establishing an optimal transfection protocol, we evaluated the transfection profile of complexes carrying A1AT-mRNA and confirmed the production of A1AT in transfected bronchial epithelial cells. The influence of nebulization process towards the biological activity of IVT-mRNA was investigated in details. We also developed an improved protocol to guarantee the transfection efficiency of nebulized IVT-mRNA lipoplexes. Since AATD is not caused by a lack of protein production but an inability to secrete functional A1AT protein, it is important to evaluate the functionality of the secreted A1AT from cells transfected by nebulized IVTmRNA formulation. To that end, the function of secreted A1AT was tested in trypsin and elastase inhibition assay. Taken together, the data obtained in current study indicate that nebulization of lipoplexes containing A1AT-mRNA is feasible for in vitro production of functional A1AT.

\section{Materials And Methods}




\section{Materials}

Stabilized, non-immunogenic messenger RNA encoding Metridia luciferase (MetLuc-mRNA), green fluorescent protein (GFP-mRNA) and human alpha-1-antitrypsin (A1AT-mRNA) were generously provided by Ethris $\mathrm{GmbH}$ (Planegg, Germany). Lipofectamine2000 was obtained from Invitrogen $(1 \mathrm{mg} / \mathrm{ml}$, Darmstadt, Germany). 4,6-diamidino-2-phenylindole (DAPI) was purchased from Life technologies $\mathrm{GmbH}$ (Karlsruhe, Germany). 3-(4,5-dimethyl-2-tetrazolyl)-2,5-diphenyl-2H-tetrazolium bromide (MTT) solution was purchased from Roche ${ }^{\circledR}$ Applied Science (Indianapolis, USA). All the other reagents and solvents were of the highest purity commercially available.

\section{Cell Culture}

Human bronchial epithelial cells (16HBE) were generously provided by Prof. Dr. Dieter C. Gruenert (University of California at San Francisco, CA, USA). The cells were cultured in a $75 \mathrm{~cm}^{2}$ culture flask in Ham's F-12K (Kaighn's) Medium (Gibco, Life Technologies, Germany) supplemented with $10 \%$ of heatinactivated fetal bovine serum (Gibco, Life Technologies, Germany) and $5 \mathrm{ml}$ of penicillin/streptomycin (10.000 units $/ \mathrm{ml}$, Gibco, Life Technologies, Germany). Cells were incubated at $37^{\circ} \mathrm{C}$ in an incubator (Heraeus Instruments $\mathrm{GmbH}$, Hanau, Germany) in $5 \% \mathrm{CO}_{2}$ atmosphere. The cells were split when they were $90 \%$ confluent. Unless specified, cells were pre-seeded in 24-well-plates at a density of $7.5 \times 10^{4}$ cells/well $24 \mathrm{~h}$ before the transfection experiments.

\section{Preparation of IVT-mRNA Complexes}

IVT-mRNA was formulated with Lipofectamine2000 in serum-free OptiMem (Gibco, Life Technologies, Germany) or serum-free Ham's F-12K medium (Gibco, Life Technologies, Germany) according to the manufacturer's instructions at RT (room temperature). For example, $50 \mu$ l solutions containing $6 \mu$ IVTmRNA $(0.1 \mu \mathrm{g} / \mu \mathrm{l})$ was gently mixed with $50 \mu \mathrm{l}$ solution containing certain amount of Lipofectamine2000 (e.g. Condition 1: $2.4 \mu \mathrm{l}$, Condition 2: $3.6 \mu \mathrm{l}$, Condition 3: $4.8 \mu \mathrm{l}$ ). The resulting formulation was incubated at $25{ }^{\circ} \mathrm{C}$ for 10 minutes prior to further use. Aliquots of the final solution were added to the cells.

\section{Size Measurements}

The IVT-mRNA/Lipofectamine2000 complexes were prepared in two settings using above-described methods at RT. $1^{\text {st }}$ Setting: $1.2 \mu \mathrm{l}, 2.4 \mu \mathrm{l}$ and $3.6 \mu \mathrm{l}$ of Lipofectamine2000 in $50 \mu \mathrm{l}$ OptiMem were mixed with $2 \mu \mathrm{l}, 4 \mu \mathrm{l}, 6 \mu \mathrm{l}$ MetLuc-mRNA in $50 \mu \mathrm{l}$ OptiMem respectively; $2^{\text {nd }}$ Setting: $2.4 \mu \mathrm{l}, 3.6 \mu \mathrm{l}, 4.8 \mu \mathrm{l}$ of Lipofectamine2000 in $50 \mu$ l OptiMem was incubated with $6 \mu$ l of MetLuc-mRNA in $50 \mu$ OptiMem, $900 \mu l$ of OptiMem was added to each sample after the incubation. The particle sizes of these complexes were determined with a Zetasizer (Brookhaven Instruments, Long Island, NY, USA) at $25^{\circ} \mathrm{C}$. For the measurement, $1 \mathrm{ml}$ of IVT-mRNA solution was pipetted into a cuvette.

\section{Transfection of Cultured Cells}


If not specified otherwise, transfection studies were performed in 24-well plates. After the removal of growth medium, cells were rinsed with PBS (Gibco, Germany). $450 \mu \mathrm{l}$ of serum-free OptiMEM or serumfree Ham's F-12K medium were added per well, and $50 \mu$ IVT-mRNA complexes (prepared as described above) were subsequently added in replicates of four or more. The complexes were incubated with the cells for $2 \mathrm{~h}$ at $37^{\circ} \mathrm{C}$ in a humidified $5 \% \mathrm{CO}_{2}$ enriched atmosphere, the transfection medium was replaced with $1 \mathrm{ml}$ fresh culture medium supplemented with 10\% FBS and 1\% (v/v) penicillin/streptomycin. Transfection aliquots of supernatants were collected at predetermined time points. The cell culture medium was replaced with fresh one after each sampling. Naked IVT-mRNA was used as a negative control.

\section{Luciferase Assay}

The MetLuc-mRNA/Lipofectamine2000 complexes were prepared in two schemes: 1) $2.4 \mu \mathrm{l}$ (Condition 1), $3.6 \mu \mathrm{l}$ (Condition 2) or $4.8 \mu \mathrm{l}$ (Condition 3) Lipofectamine2000 in $50 \mu \mathrm{l}$ solutions were mixed with $6 \mu \mathrm{l}$ MetLuc-mRNA $(0.1 \mu \mathrm{g} / \mu \mathrm{l})$ in $50 \mu \mathrm{l}$ solutions; 2) $1.2 \mu \mathrm{l}$ (Condition 1), $2.4 \mu \mathrm{l}$ (Condition 2) or $3.6 \mu \mathrm{l}$ (Condition 3) Lipofectamine2000 were mixed respectively with $2 \mu \mathrm{l}$ (Condition 1), $4 \mu \mathrm{l}$ (Condition 2) or $6 \mu \mathrm{l}$ (Condition 3) MetLuc-mRNA $(0.1 \mu \mathrm{g} / \mu \mathrm{l})$ with a final volume of $100 \mu \mathrm{l}$. $16 \mathrm{HBE}$ cells were incubated with above MetLuc-mRNA/Lipofectamine2000 complexes at the volume of $50 \mu \mathrm{l} /$ well for $2 \mathrm{~h}$. The transfection efficiency was evaluated $24 \mathrm{~h}$ after adding complexes to the cells. $50 \mu \mathrm{l}$ of supernatant from each sample were added to a 96-well plate. This was followed by addition of $40 \mu$ of the Metridia luciferase substrate (coelenterazine, InvivoGen, France). The emitted light was measured with a microplate reader (FLUOstar Optima, BMG Labtech, Germany) and its activity is expressed in relative light units.

\section{Fluorescence Microscopy}

For transfection of 16HBE cells with IVT-mRNA encoding GFP, complexes were prepared as described above. $2.4 \mu \mathrm{l}$ (Condition 1) or $3.6 \mu \mathrm{l}$ (Condition 2) Lipofectamine2000 in $50 \mu \mathrm{l}$ medium was mixed respectively with $4 \mu \mathrm{l}$ (Condition 1 ) or $6 \mu \mathrm{l}$ (Condition 2) GFP-mRNA $(0.1 \mu \mathrm{g} / \mu \mathrm{l})$ in serum-free OptiMem or serum-free Ham's F-12K medium to prepare complexes for transfection. To visualize GFP-mRNA transfected cells, $16 \mathrm{HBE}$ cells were seeded at a density of $15.0 \times 10^{4}$ cells/well in IBIDI 8-well slides (IBIDI $\mathrm{GmbH}$, Germany) $24 \mathrm{~h}$ before transfection to reach a monolayer. The complexes were incubated with the cells for $2 \mathrm{~h}$ in an incubator. The transfection efficiency was evaluated $24 \mathrm{~h}$ after transfection using fluorescence microscopy (Zeiss Axiovert 200 M, Carl Zeiss Microscopy GmbH, Germany).

\section{MTT based Cytotoxicity Assay}

$16 \mathrm{HBE}$ cells were plated into a 96 -well plate $\left(2.0 \times 10^{4}\right.$ cells/well $) 24 \mathrm{~h}$ before transfection with IVT-mRNA lipoplexes. After $2 \mathrm{~h}$ of incubation, the complexes were removed and $100 \mu \mathrm{l}$ of fresh medium was added. Cell viability was measured $24 \mathrm{~h}$ after transfection. To that end, $10 \mu \mathrm{l}$ of the MTT solution was added to the cells and incubated for $2 \mathrm{~h}$. Subsequently, $100 \mu \mathrm{l}$ of the solubilization solution (10\% SDS in $0.01 \mathrm{M}$ $\mathrm{HCL}$, Roche ${ }^{\circledR}$ Applied Science, Indianapolis, USA) was added. After $24 \mathrm{~h}$, the absorbance was measured with a microplate reader (FLUOstar Optima, BMG Labtech, Germany) at $600 \mathrm{~nm}$ with a reference above 
$650 \mathrm{~nm}$. Untreated cells were used as the control group. The cell viability was calculated as a relative value (in percentage) compared to control group.

\section{Nebulization}

For nebulization experiments we used an improved transfection protocol to ensure a higher transfection efficiency after being aerosolized. The IVT-mRNA/Lipofectamine2000 complexes were prepared by mixing $18 \mu \mathrm{l}$ MetLuc-mRNA or A1AT-mRNA with $7.2 \mu \mathrm{l}$ (Condition 1), $10.8 \mu \mathrm{l}$ (Condition 2), $14.4 \mu \mathrm{l}$ (Condition 3) Lipofectamine2000 in serum-free OptiMem or serum-free Ham's F-12K medium with a total volume of $100 \mu \mathrm{l}$. The above solutions were incubated for 10 minutes at RT. This was followed by addition of $2900 \mu \mathrm{l}$ medium. The solution was divided into two fractions. A small fraction was kept apart and was used as a non-nebulized control. The other part was pipetted into the PARI Boy ${ }^{\circledR}$ Jet-Nebulizer (Pari $\mathrm{GmbH}$, Germany) and was aerosolized for 5 minutes, the aerosolized solution was collected in a microcentrifuge tube (Eppendorf ${ }^{\mathrm{T} M}$ PCR Clean, ThermoFisher Scientific, Germany) and used as the "nebulized" group. Subsequently, both fractions $(20 \mu \mathrm{l} /$ well) were pipetted onto a 96 -well plate in which $16 \mathrm{HBE}$ cells were pre-seeded at a density of $3.0 \times 10^{4} \mathrm{cells} /$ well one day before. The complexes were incubated with the cells for $2 \mathrm{~h}$. After their removal $0.1 \mathrm{ml}$ of fresh culture medium was added. The luciferase activity or the A1AT related assay was measured $24 \mathrm{~h}$ after transfection.

\section{Detection of Alpha-1-antitrypsin using Enzyme-linked Immunosorbent Assay (ELISA)}

For the detection of alpha-1-antitrypsin (A1AT) we used an alpha-1-antitrypsin human ELISA kit (Abcam, Cambridge, United Kingdom). In this assay a 96-well plate is coated with a capture antibody, which is specific to recognize alpha-1-antitrypsin. Cell supernatants were collected $24 \mathrm{~h}$ after transfecting $16 \mathrm{HBE}$ cells with A1AT-mRNA. Supernatant was centrifuged at $3000 \times \mathrm{g}$ for 10 minutes to remove cell debris. Subsequently, $10 \mu \mathrm{l}$ of supernatants were diluted in medium. $50 \mu \mathrm{l}$ of standard solutions or samples were pipetted onto the microplate. The wells were covered with a sealing tape and incubated for $2 \mathrm{~h}$. Then 50 $\mu \mathrm{l}$ of a biotinylated alpha-1-antitrypsin antibody (Abcam, Cambridge, United Kingdom) were added. After $1 \mathrm{~h}$ of incubation, $50 \mu \mathrm{l}$ of the streptavidin-peroxidase conjugate was added. After each step the plate was washed 5-times with a mild detergent. Subsequently a chromogen substrate and finally a stop solution were added. The absorbance was measured with a plate reader (FLUOstar Optima, BMG Labtech, Germany) at $405 \mathrm{~nm}$.

\section{Alpha-1-antitrypsin Functional Assay}

Trypsin degradation: $5 \mu \mathrm{l}$ of trypsin solution $(0.02 \mathrm{U} / \mu \mathrm{l}$, Abcam, United Kingdom) were added to $45 \mu \mathrm{l}$ trypsin assay buffer. $50 \mu$ supernatants of A1AT-mRNA transfected cells were added to this solution. After 10 minutes of incubation, $50 \mu$ trypsin substrate solution (Na-Benzoyl-DL-arginine-b-naphthylamide hydrochloride, Abcam, United Kingdom) was added. The solution was mixed by vortexing. The colorimetric reaction was followed by measuring fluorescence at $405 \mathrm{~nm}$ a plate reader (FLUOstar Optima, BMG Labtech, Germany). 
Elastase degradation: To perform this assay, $5 \mu$ l of the elastase solution $(0.1 \mathrm{U} / \mu \mathrm{l}$, from EnzChek Elastase Assay Kit, Molecular Probes, Life Technologies, Germany) were added to $45 \mu$ l of the reaction buffer ( $1 \mathrm{M}$ Tris- $\mathrm{HCl}, \mathrm{pH} 8$, containing $2 \mathrm{mM}$ sodium azide). Afterwards $50 \mu \mathrm{l}$ of supernatant from cells transfected with IVT-mRNA encoding alpha-1-antitrypsin was added and incubated at $37^{\circ} \mathrm{C}$ for 10 minutes. The reactions were diluted in $400 \mu \mathrm{l}$ reaction buffer containing the chromogenic substrate (160 nmol, $N$-Methoxysuccinyl-Ala-Ala-Pro-Val-p-nitroanilide, MeO-SucAAPV-pNA, Sigma). The colorimetric reaction was evaluated by measuring the absorbance of $200 \mu$ reaction mixtures at $410 \mathrm{~nm}$ with a plate reader (FLUOstar Optima, BMG Labtech, Germany).

\section{Immunofluorescence}

16HBE cells were transfected with IVT-mRNA encoding A1AT as described above. IVT-mRNA lipoplexes were removed after $2 \mathrm{~h}$ of incubation. Fresh cell culture medium and Brefeldin-A was added. After $24 \mathrm{~h}$ cells were washed 3 -times with PBS. To fixate the cells in their current state, $1 \mathrm{ml}$ of a fixation buffer ( $4 \%$ paraformaldehyde in PBS, BioLegend, USA) was used. After an incubation period of 10 minutes the cells were washed with PBS again. Subsequently, $1 \mathrm{ml}$ of fix/perm buffer (BD Biosciences, Germany) was added. The cells were incubated with the buffer for 15 minutes. Afterwards a human A1AT specific antibody (NBP1-90309, Novus biologicals, USA) was added. To ensure bonding between antigen of interest and the detection antibody the incubation time was $1 \mathrm{~h}$ at room temperature (RT). The cells were washed again with PBS to remove an excess of antibodies. To keep the cells permeabilized we treated them again with a perm/wash buffer. Subsequently, a Goat anti-Rabbit IgG ReadyProbes ${ }^{\mathrm{TM}}$ secondary antibody flagged with AlexaFluor ${ }^{\circledR} 594$ (Life Technologies, Germany) was added. Debris was removed by washing the cells with PBS. For intracellular orientation, $300 \mu$ LAPI (300 nM in PBS) was used to stain nucleus. Two controls were used, one using a non-specific antibody as well as the secondary antibody and for the second only the secondary antibody.

\section{Statistical Analysis}

Data for all bar charts were prepared using means and error bars that correspond to standard deviations. Statistical analysis was performed using Prism 7 (GraphPad Software Inc, USA). An ANOVA followed by Bonferroni test was applied for comparisons between different groups. The statistical significance of differences between two groups were analysed by two-tailed student's $t$-tests, and differences were considered statistically significant when $P<0.05$.

\section{Results}

\section{Optimization and Characterization of the Transfection Process}

\section{Finding the Optimal Transfection Condition}

The IVT-mRNA/Lipofecttamine200 complexes were prepared in OptiMem, a medium specially designed for transfection. Dynamic light scattering measurements revealed that the size of IVT- 
mRNA/Lipofectamine2000 complexes prepared under different conditions and settings were typically a few hundred nanometers, as depicted in Table 1 (Non-nebulized). In order to evaluate the influence of components ratio on the transfection efficiency of IVT-mRNA lipoplexes, increased amounts of Lipofectamine2000 were firstly formulated with a fixed amount of IVT-mRNA. The IVT-mRNA encoding secreted Metridia luciferase (MetLuc-mRNA) was selected as a reporter system to transfect human bronchial epithelial cells (16HBE). As shown in Figure1A, there were no significant difference in the luciferase activities between the studied conditions, indicating that complexes prepared by mixing Lipofectamine2000 with IVT-mRNA at these ratios transfect $16 \mathrm{HBE}$ cells with almost equal efficiency.

Table 1. Size of IVT-mRNA/Lipofectamine2000 lipoplexes.

\begin{tabular}{ccccc}
\hline $\begin{array}{c}\text { IVT-mRN/Lipofectamine2000 } \\
\text { lipoplexes }\end{array}$ & $\begin{array}{c}\text { Amounts of } \\
\text { Lipofectamine2000 } \\
(\mu \mathrm{L})\end{array}$ & $\begin{array}{c}\text { Amounts of } \\
\text { IVT-mRNA } \\
(\mu \mathrm{L})\end{array}$ & $\begin{array}{c}\text { Size (nm) } \\
\text { Non- } \\
\text { nebulized }\end{array}$ & $\begin{array}{c}\text { Size (nm) } \\
\text { Nebulized }\end{array}$ \\
\hline 1st Setting-condition 1 & 2.4 & 6.0 & $397 \pm 118$ & $649 \pm 173$ \\
1st Setting-condition 2 & 3.6 & 6.0 & $467 \pm 67$ & $543 \pm 123$ \\
1st Setting-condition 3 & 4.8 & 6.0 & $324 \pm 46$ & $628 \pm 76$ \\
2nd Setting-condition 1 & 1.2 & 2.0 & $458 \pm 89$ & $737 \pm 113$ \\
2nd Setting-condition 2 & 2.4 & 4.0 & $480 \pm 74$ & $676 \pm 138$ \\
2nd Setting-condition 3 & 3.6 & 6.0 & $378 \pm 84$ & $586 \pm 161$
\end{tabular}

The IVT-mRNA lipoplexes were prepared by mixing different amounts Lipofectamine2000 with IVT-mRNA. The complexes were prepared in OptiMem. After a 10 minute incubation period the size measurement was performed. The data represent hydrodynamic diameter $\pm S D, n=3$.

Subsequently, $2 \mu \mathrm{l}$ (Condition 1), $4 \mu \mathrm{l}$ (Condition 2) or $6 \mu$ l (Condition 3) of MetLuc-mRNA were mixed with Lipofectamine2000 at the volume ratio of 1:0.6 to reveal whether increased amount of IVT-mRNA could translate into higher transfection efficiencies. The results showed that lipoplexes containing different amounts of MetLuc-mRNA but prepared and incubated with the same medium resulted in a similar transfection profile (Figure 1B). To determine the influence of different media on the transfection efficiency, the complexes were first prepared in OptiMem or the medium routinely used for growing $16 \mathrm{HBE}$ cells (Ham's F-12K), both cases were serum-free throughout the study. The transfection efficiency was evaluated $24 \mathrm{~h}$ after adding complexes to the cells by measuring the luciferase activity. When MetLucmRNA complexes were prepared and incubated with 16HBE cells in Ham's F-12K medium, the levels of luciferase activity were significantly lower than counterparts prepared by OptiMem (Figure 1B).

In the next set of experiments, we employed other solutions that are commonly used in a clinical setting to prepare IVT-mRNA complexes. To that end, we transfected 16HBE cells with complexes prepared in glucose, sucrose or sodium chloride and evaluated their transfection efficiencies. To our surprise, luciferase activity mediated by IVT-mRNA/Lipofectamine2000 complexes prepared in a $5 \%$ glucose or $5 \%$ 
sucrose solution was hardly measurable. Maximal levels of luciferase activity obtained were 87,963 and 25,240 RLU for $5 \%$ glucose and $5 \%$ sucrose, respectively. On the other hand, lipoplexes prepared in saline were relatively more efficient, as demonstrated in Figure 1C. Maximal levels of luciferase activity obtained were above 1,000,000 RLU. However, it is worth to note that the transfection efficiency mediated by complexes prepared in saline were still low compared to the case of OptiMem.

In order to improve the transfection efficiency that mediated by glucose or sucrose solution, we first prepare MetLuc-mRNA/Lipofectamine2000 lipoplexes using $0.9 \%$ sodium chloride solution and subsequently incubated them with $16 \mathrm{HBE}$ cells in $5 \%$ glucose or $5 \%$ sucrose. As shown in Figure 1D, the transfection efficiencies of these lipoplexes showed some increase compared to those lipoplexes prepared in $5 \%$ glucose or $5 \%$ sucrose. But the level of transfection was lower than that prepared and incubated in $0.9 \%$ sodium chloride solution, suggesting the sodium chloride ions are relatively advantageous in facilitating transfection of the lipoplexes. Based on all the above results, we chose OptiMem and Ham's F-12K medium to prepare IVT-mRNA/Lipofectamine2000 lipoplexes and incubate the formulation with $16 \mathrm{HBE}$ cells in the following studies.

\section{Duration of Protein Production}

IVT-mRNA is considered to be a relatively unstable molecule compared to other types of nucleic acids, which would limit the employment of IVT-mRNA as a long-term transfection tool. Transfection of cultured cells mediated by cationic lipids based IVT-mRNA complexes is expected to be transient. To verify this expectation, $16 \mathrm{HBE}$ cells transfected with MetLuc-mRNA complexed with Lipofectamine2000 were monitored for luciferase production over a period of several days. Three Lipofectamine2000 to MetLucmRNA ratios were tested. To ensure maximal level of protein production, the MetLucmRNA/Lipofectamine2000 complexes were prepared using OptiMem. As shown in Figure 2, significant levels of luciferase activity could be detected for four days. The highest levels of protein production were found $24 \mathrm{~h}$ after adding complexes to the cells.

\section{Evaluating Transfection Efficiency via GFP-mRNA}

In addition to evaluating total levels of protein production in 16HBE cells we also assessed numbers of transfected cells using green fluorescent protein as a reporter. To that end, we employed IVT-mRNA encoding green fluorescent protein (GFP-mRNA) to prepare complexes with Lipofectamine2000. The transfection efficiency was evaluated $24 \mathrm{~h}$ after adding complexes to the cells by visualising transfected cells via a fluorescent microscope (Figure 3). Consistent to the result obtained from luciferase-mRNA based transfection, the majority of cells transfected by GFP-mRNA/Lipofectamine2000 lipoplexes prepared in OptiMem showed a positive signal for GFP (Figure 3A), while less GFP positive cells were observed in the group transfected by GFP-mRNA lipoplexes prepared in Ham's F-12K medium (Figure 3B).

\section{Transfection with IVT-mRNA Encoding Alpha-1-antitrypsin (A1AT)}

\section{A1AT Expression Mediated by A1AT-mRNA Lipoplexes}


We then evaluated the transfection efficiency of complexes prepared by mixing Lipofectamine 2000 with IVT-mRNA encoding alpha-1-antitrypsin (A1AT-mRNA). To confirm the expression of A1AT, we stained the produced protein inside $16 \mathrm{HBE}$ cells with an antibody labelling method. This technique is based on indirect immunohistochemical staining using lactone antibiotic Brefeldin-A to inhibit transfected cells from secreting the produced A1AT. The inhibited cells are not able to secrete proteins via vesicles. After blocking the secretion of proteins, intracellular A1AT was labelled by specific antibody and was visualized via a secondary antibody tagged with red-fluorescent dye. Strong red signal could be observed within cells transfected by A1AT-mRNA/Lipofectamine2000 complexes as shown in Figure $\mathbf{4}$ while none of red signal could be detected in untreated cells as well as in transfected cells that treated with an unspecific primary antibody or secondary antibody (data not shown).

To further detect the amount of secreted A1AT in transfected 16HBE cells, an enzyme linked immunosorbent assay (ELISA) was performed. Figure 5A demonstrates a representative ELISA microplate. The amounts of A1AT in samples transfected by A1AT-mRNA/Lipofectamine2000 complexes were calculated using standard curve method. The results are presented in Figure 5B. Cells transfected with lipoplexes prepared in OptiMem showed a slightly higher rate of secreted A1AT. The maximal levels of A1AT were secreted by cells transfected with the lipoplexes prepared at the highest Lipofectamine2000 to A1AT-mRNA ratios (Condition 3). However, there is no significant differences between "OptiMem" group and "Ham's F-12K" group, revealed by statistical analysis.

\section{Cell Viability after Transfection with Different IVT-mRNA Lipoplexes}

An MTT assay was employed to assess the impact of lipoplexes carrying different types of IVT-mRNA (i.e. MetLuc-mRNA, GFP-mRNA and A1AT-mRNA) on the viability of $16 \mathrm{HBE}$ cells (Figure 6). OptiMem or Ham's F-12K was used to prepare IVT-mRNA complexes. Toxicity was evaluated $24 \mathrm{~h}$ after transfection, which is the time when the transfected cells need to produce maximal levels of the protein of interest and require to deal with possible degraded products. Toxicity induced by formulations prepared in OptiMem carrying MetLuc-mRNA in condition 3 showed mild toxicities (Figure 6A), while none of the tested GFPmRNA/Lipoplexes (Figure 6B) and A1AT-mRNA/Lipoplexes (Figure 6C) displayed significant toxicity in 16HBE cells.

\section{Nebulization of IVT-mRNA Complexes}

\section{Particle Size and Transfection Efficiency of Lipoplexes after the Nebulization}

In order to confirm whether IVT-mRNA lipoplexes could tolerate the nebulization process, we compared the change in particle size of MetLuc-mRNA/Lipofectamine2000 complexes before and after nebulization, then evaluated the luciferase activity induced by nebulized MetLucmRNA/Lipofectamine2000 complexes with their non-nebulized counterparts. After nebulization, an increase in the particle size can be observed in all the settings (Table 1, "Nebulized"). Afterwards, we transfected 16HBE cells with nebulized MetLuc-mRNA complexes and non-nebulized control that prepared in different media and with different Lipofectamine2000 to IVT-mRNA ratios to evaluate the 
impact of the nebulization process on transfection efficiency. As shown in Figure 7, all groups of the nebulized MetLuc-mRNA/Lipofectamine2000 complexes that prepared with the standard protocol (Protocol 1) were not as efficient in transfecting 16HBE cells as their non-nebulized counterparts. A significant decrease in transfection efficiency was detected in all nebulized lipoplexes prepared by protocol 1, regardless of the charge ratios or the medium that applied (Figure 7,Protocol 1), implying that Lipofectamine2000 could not protect IVT-mRNA against the shear force induced by the nebulizer in a good way. As a result, we needed to develop an improved protocol in which higher transfection efficiencies of the nebulized formulations could be reached. To that end, we kept the same Lipofectamine2000 to IVT-mRNA ratio but used triple amounts of IVT-mRNA to prepare the lipoplexes (Protocol 2). The transfection efficiency of MetLuc-mRNA lipoplexes prepared by protocol 2 and their nebulized counterpart was evaluated, the results are shown in Figure 7. The nebulized lipoplexes prepared in OptiMem using protocol 2 showed a significantly higher efficiency than the nebulized complexes prepared according to protocol 1 in all conditions (Figure 7A). When complexes were prepared in Ham's F$12 \mathrm{~K}$ medium (Figure 7B), the differences between the standard transfection (protocol 1) and the improved nebulization protocol (protocol 2) were significant in condition 1 and condition 3.

\section{Cell Viability following Transfection with Protocol 2}

After obtaining sufficient transfection efficiency of the nebulized IVT-mRNA/Lipofectamine2000 complexes, it was crucial to evaluate their toxicity on 16HBE cells. The MTT-assay was performed $24 \mathrm{~h}$ after transfection with nebulized lipoplexes using protocol 2. As demonstrated in Figure 8, lipoplexes prepared in OptiMem showed considerably enhanced cytotoxicity towards $16 \mathrm{HBE}$ cells in all three conditions (Figure 8A). Similarly, 16HBE cells incubated with IVT-mRNA lipoplexes prepared in Ham's F$12 \mathrm{~K}$ medium also showed significantly reduced viability on in condition 1 and condition 3 (Figure 8B).

\section{Nebulization of A1AT-mRNA/Lipofectamine2000 Complexes}

The main focus of current study was to investigate the transfection efficiency of nebulized lipoplexes formulations containing A1AT-mRNA and to confirm that the secreted A1AT protein was still functional. We transfected $16 \mathrm{HBE}$ cells with nebulized A1AT-mRNA/Lipofectamine2000 complexes prepared by protocol 2 as described above and non-nebulized control to evaluate the impact of the nebulization process on the transfection efficiency. An ELISA was employed to assess the amount of secreted A1AT. As shown in Figure 9, the most abundant A1AT production was observed in the non-nebulized complexes prepared by mixing Lipofectamine 2000 and A1AT-mRNA in condition 3. Statistical analysis suggests that there is a significant difference in secreted A1AT from the nebulized and non-nebulized fraction of lipoplexes prepared in condition 3. The nebulized samples are not as efficient transfecting $16 \mathrm{HBE}$ cells as the non-nebulized counterparts. However, the amount of secreted A1AT from nebulized fraction of condition 3 was comparable to counterparts in condition 1 and condition 2. Collectively, these data indicate that both the nebulized and non-nebulized A1AT-mRNA encoded A1AT protein (at least partially) is folded and modified appropriately within the airway epithelium to enable secretion out of the 
endoplasmic reticulum and into cell culture medium, protein levels could be successfully detected in the supernatant.

After confirming the presence of A1AT product in the supernatants of cells transfected by nebulized A1ATmRNA/Lipofectamine2000 complexes, it is important to further verify whether the secreted protein was functional. A1AT is a general serine protease inhibitor, it is not only an inhibitor of the serine protease trypsin, but also can inhibit many other serine proteases, e.g. elastase. To that end, two functional assays were performed. We first evaluated the function of secreted A1AT in inhibiting the activity of trypsin. Trypsin is a serine protease that can hydrolyses chromogenic substrate, Na-Benzoyl-DL-arginine-bnaphthylamide hydrochloride. The inhibition of the trypsin activity, e.g. by A1AT, will prevent this reaction to occur. The trypsin activity inhibited by secreted A1AT from supernatants of "nebulized" or "nonnebulized" A1AT-mRNA/Lipofectamine2000 complexes transfected cells was measured. Trypsin activity was maximally inhibited by an extent of $60 \%$ in samples from "non-nebulized lipoplexes in condition 3 " (Figure 10A), which is related to the amounts of detected A1AT in the supernatants. A1AT from cells transfected by "nebulized" lipoplexes could inhibit $40 \%-46 \%$ of the trypsin activity and the inhibition rates among samples prepared in different conditions were similar (Figure 10A).

The primary function of A1AT is to inhibit the activity of elastase. In order to evaluate the function of secreted A1AT in the supernatants of cells transfected by A1AT-mRNA lipoplexes, we also performed an anti-elastase assay in which elastase and its synthetic substrate ( $N$-Methoxysuccinyl-Ala-Ala-Pro-Val- $p$ nitroanilide) are used to determine the extent of inhibition caused by A1AT [42]. The rate of enzymatic hydrolysis of the substrate is followed by the increase in absorbance due to the release of free $p$ nitroanilide cleaved from the substrate. Similar to the results of trypsin assay, A1AT from cells transfected by "nebulized" lipoplexes could inhibit the elastase activity, and the inhibition rates ( 35\%) were comparable among samples prepared in different conditions (Figure 10B). A1AT presented in samples from "non-nebulized" lipoplexes inhibited the elastase activity to levels lower than $59 \%$ compare to the control, with a maximally inhibition rate of $54 \%$ in samples from "condition 2" (Figure 10B).

\section{Discussion}

Establishing safe, efficient and reproducible nebulized IVT-mRNA formulations will become the basis of successful gene therapy for various lung based and respiratory diseases, such as cystic fibrosis and AATD. However, challenges remain in optimizing IVT-mRNA delivery to the lung $[19,20]$, and there are yet very few studies focusing on the nebulized IVT-mRNA formulations designed for AATD treatment. As a result, we set out to investigate optimal conditions for the preparation of A1AT-mRNA/Lipofectamine2000 complexes that can produce sufficient A1AT after the nebulization process.

Since Lipofectamine2000 has been demonstrated in several studies as an efficient transfecting agent in cultured cells [41, 43, 44], we employed this cationic lipid carrier throughout current study. It has been suggested that the ratio, at which cationic lipids and IVT-mRNA are mixed determines levels of transfection as well as cytotoxicity induced by the formulation [45]. In our study, significant levels of 
luciferase activity could be detected for four days and none of the IVT-mRNAcomplexs displayed significant toxicity although there was no difference in the transfection profile of the lipoplexs containing different amounts of MetLuc-mRNA. Another factor that has a strong impact on transfection efficiency is the medium in which complexes are prepared and incubated with cells [45]. When MetLuc-mRNA complexes were prepared and incubated with 16HBE cells in OptiMem medium, the levels of luciferase activity were significantly higher than the counterparts prepared by Ham's F-12K, consistent with the results obtained from GFP-mRNA/Lipofectamine2000 based transfection. The transfection efficiencies mediated by complexes prepared in glucose, sucrose or sodium chloride were much lower compared to the case of OptiMem. Furthermore, all groups of the nebulized MetLuc-mRNA/Lipofectamine2000 complexes were not as efficient in transfecting $16 \mathrm{HBE}$ cells as their non-nebulized counterparts, implying that Lipofectamine2000 could not protect IVT-mRNA against the shear force induced by the nebulizer in a good way. After nebulization, an increase in the particle size, giving rise to a form of instability of the IVTmRNA/Lipofectamine2000, could be observed in all the settings. However, the complexes remain in a nanometer size range following nebulization, which may still enable them to cross biological membranes and deliver their cargo into the cultured cells [46]. When triple amounts of IVT-mRNA was used to prepare the lipoplexes, the nebulized MetLuc-mRNA lipoplexes showed significantly higher transfection efficiency and considerably enhanced cytotoxicity. The increased initial amount of IVT-mRNA could ensure more IVT-mRNA molecules survive the nebulization process and there will be more functional IVT-mRNA molecules in the nebulized fractions in this case, and the presence of more Lipofectamine2000 may help to alleviate the shear force during nebulization but also increased cytotoxicity in a dose dependent manner [25][47]. We and others have demonstrated in previous studies that polyplexes prepared by cationic polymers such as branched or linear polyethylenimine could protect IVT-mRNA during the nebulization process and their transfection efficiency did not significantly compromise after the nebulization $[25,48,49]$. However, the transfection efficiency achieved by IVT-mRNA complexed with cationic lipids was much higher than counterparts formulated with cationic polymers in general, regardless of non-nebulized formulation or nebulized one as being proved by previous studies $[25,41]$.

In current study, our main focus was to investigate the transfection efficiency of nebulized lipoplexes formulation containing A1AT-mRNA and to confirm that the secreted A1AT protein was still functional. Consistent with the results discussed above, the abundant A1AT production was observed in $16 \mathrm{HBE}$ cell transfected by A1AT-mRNA/Lipofectamine2000 complexes before or after nebulization. A1AT is a general serine protease inhibitor, it is not only an inhibitor of the trypsin, but also can inhibit many other serine proteases, e.g. elastase. In fact, the primary function of A1AT is to inhibit activity of neutrophil elastase [50]. Elastase plays a significant role in the human immune system, since neutrophil granulocytes secrete it against gram-negative bacteria [51]. However, when elastase secretion is out of control, the over expressed elastase is able to cleave components of the extracellular matrix such as elastin, a macromolecule that provides the elastic recoil of the lung [52]. To inhibit neutrophil elastase, the active site amino acids Met 358 - Ser 359 within A1AT will form a non-covalent interaction with the reactive site pocket of the elastase. Under normal condition, this is a so-called suicide interaction for both proteins [28]. According to the results obtained from functional analysis, the activity of elastase was inhibited with 
an extent of $54 \%$ and $35 \%$ by A1AT-mRNA/Lipofectamine 2000 formulations before or after the nebulization, while $60 \%$ and $40 \%-46 \%$ for the case of anti-trypsin assay, respectively. This implied that the secreted A1AT produced from both the nebulized and non-nebulized formulations could be enzymatically active in inhibiting the activity of trypsin as well as elastase. These levels of secreted A1AT hold the potency to decrease neutrophil elastase activity within the lung of AATD patients, and thereby alleviate or even prevent alveolar degradation and emphysema that observed in AATD patients. Collectively, the overall results suggest the nebulized A1AT-mRNA formulation might be a promising solution for the treatment of AATD.

Even though A1AT produced from nebulized formulation could inhibit the activity of trypsin and elastase, there is a significant decrease in the amount of secreted A1AT from the nebulized A1AT-mRNA lipoplexes compared to the non-nebulized fraction. This could be one indication that Lipofecatine2000 could not well-protect A1AT-mRNA during the nebulization process. Further improvements could be done by employing the vibrating mesh nebulizer by which moderate shear forces are generated during nebulization, instead of the jet nebulizer whose shear forces could not be resisted by IVT-mRNA lipoplexes in current study. Nevertheless, Lipofectamin2000 based formulations may still encounter limitations and challenges in the process of further development considering its well known in vivo toxicity, and they may not be effective when applied for in vivo purposes as the way they worked in cultured cells. Moreover, the most efficient IVT-mRNA/Lipofectamine2000 formulations in current study were prepared in OptiMem, it is probably not clinically practical to use cell culture media as the formulation solution. As a result, it will need further works to improve the potency of nebulized A1AT-mRNA formulations. For example, an alternative approach to improve the potency of A1AT-mRNA based therapeutic would be the utilization of novel biomaterials that specifically developed for nebulized IVT-mRNA formulations which displayed promising results in animal applications [26]. These delivery systems with good biocompatibility may pave the road for the development of aerosolized IVT-mRNA formulations enabling safe and productive transfection in patients' airways, to be applied for the successful treatment of AATD.

\section{Abbreviations}

IVT-mRNA: in vitro transcribed messenger RNA; SARS-CoV-2: severe acute respiratory syndrome coronavirus 2; COVID-19: coronavirus disease 2019; AATD: alpha-1-antitrypsin deficiency; A1AT: alpha-1-

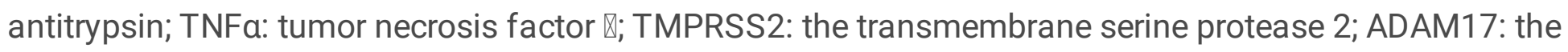
disintegrin and metalloproteinase17; A1AT-mRNA: messenger RNA encoding human alpha-1-antitrypsin; MetLuc-mRNA: messenger RNA encoding Metridia luciferase; GFP-mRNA: messenger RNA encoding green fluorescent protein; 16HBE: Human bronchial epithelial cells; RT: room temperature

\section{Declarations}

\section{Ethics approval and consent to participate}

Not applicable 


\section{Consent for publication}

Not applicable

\section{Availability of data and materials}

All data generated or analyzed during this study are included in this published article.

\section{Conflicts of interest}

The authors declare no conflict of interest.

\section{Funding}

This work was supported by the Bundesministerium für Bildung und Forschung (BMBF) under the project number 01GM1106A.

\section{Authors' contribution}

SG and JR conceived and designed the study. MD performed the experiments. MD and CX analyzed the data. JR contributed materials and analysis tools. SG, MD and CX drafted the manuscript.

\section{Acknowledgements}

The authors are grateful to Carsten Rudolph (Ethris $\mathrm{GmbH}$, Planegg, Germany) for providing SNIM-mRNA. Shan Guan would like to acknowledge funding (Förderung des leichteren Übergangs in eine Gründerexistenz) from Bayerisches Staatsministerium für Wirtschaft und Medien, Energie und Technologie.

\section{References}

1. High KA, Roncarolo MG. Gene therapy. New England Journal of Medicine. 2019;381:455-64.

2. Wang J, Peng Y, Xu H, Cui Z, Williams RO 3rd. The COVID-19 Vaccine Race: Challenges and Opportunities in Vaccine Formulation. AAPS PharmSciTech. 2020;21:225.

3. Laczkó D, Hogan MJ, Toulmin SA, Hicks P, Lederer K, Gaudette BT, et al. A Single Immunization with Nucleoside-Modified mRNA Vaccines Elicits Strong Cellular and Humoral Immune Responses against SARS-CoV-2 in Mice. Immunity. 2020.

4. Keeler AM, EIMallah MK, Flotte TR. Gene Therapy 2017: Progress and Future Directions. Clinical and translational science. 2017;10:242-8.

5. Trepotec Z, Lichtenegger E, Plank C, Aneja MK, Rudolph C. Delivery of mRNA Therapeutics for the Treatment of Hepatic Diseases. Molecular therapy: the journal of the American Society of Gene Therapy. 2019;27:794-802. 
6. Kormann MSD, Hasenpusch G, Aneja MK, Nica G, Flemmer AW, Herber-Jonat S, et al. Expression of therapeutic proteins after delivery of chemically modified mRNA in mice. Nature Biotechnology. 2011;29:154-7.

7. Tavernier G, Andries O, Demeester J, Sanders NN, De Smedt SC, Rejman J. mRNA as gene therapeutic: how to control protein expression. Journal of controlled release: official journal of the Controlled Release Society. 2011;150:238-47.

8. Sahin U, Karikó K, Türeci Ö. mRNA-based therapeutics - developing a new class of drugs. Nature Reviews Drug Discovery. 2014;13:759-80.

9. Routy JP, Boulassel M-R, Yassine-Diab B, Nicolette C, Healey D, Jain R, et al. Immunologic activity and safety of autologous HIV RNA-electroporated dendritic cells in HIV-1 infected patients receiving antiretroviral therapy. Clin Immunol. 2010;134:140-7.

10. Kübler H, Scheel B, Gnad-Vogt U, Miller K, Schultze-Seemann W, Vom Dorp F, et al. Self-adjuvanted mRNA vaccination in advanced prostate cancer patients: a first-in-man phase I/lla study. Journal for immunotherapy of cancer. 2015;3:26.

11. Kranz LM, Diken M, Haas H, Kreiter S, Loquai C, Reuter KC, et al. Systemic RNA delivery to dendritic cells exploits antiviral defence for cancer immunotherapy. Nature. 2016;534:396-401.

12. Pardi N, Hogan MJ, Pelc RS, Muramatsu H, Andersen H, DeMaso CR, et al. Zika virus protection by a single low-dose nucleoside-modified mRNA vaccination. Nature. 2017;543:248-51.

13. Pardi N, Secreto AJ, Shan X, Debonera F, Glover J, Yi Y, et al. Administration of nucleoside-modified mRNA encoding broadly neutralizing antibody protects humanized mice from HIV-1 challenge. Nature Communications. 2017;8:6-13.

14. Khoury HJ, Collins RH, Blum W, Stiff PS, Elias L, Lebkowski JS, et al. Immune responses and longterm disease recurrence status after telomerase-based dendritic cell immunotherapy in patients with acute myeloid leukemia. Cancer. 2017;123:3061-72.

15. Bahl K, Senn JJ, Yuzhakov O, Bulychev A, Brito LA, Hassett KJ, et al. Preclinical and Clinical Demonstration of Immunogenicity by mRNA Vaccines against H10N8 and H7N9 Influenza Viruses. Molecular Therapy the Journal of the American Society of Gene Therapy. 2017;25:1316-27.

16. Lederer K, Castaño D, Atria DG, Oguin TH, Wang S, Manzoni TB, et al. SARS-CoV-2 mRNA vaccines foster potent antigen-specific germinal center responses associated with neutralizing antibody generation. Immunity. 2020.

17. Jackson LA, Anderson EJ, Rouphael NG, Roberts PC, Makhene M, Coler RN, et al. An mRNA Vaccine against SARS-CoV-2 - Preliminary Report. New England Journal of Medicine. 2020.

18. Beck-Broichsitter M, Merkel OM, Kissel T. Controlled pulmonary drug and gene delivery using polymeric nano-carriers. Journal of controlled release: official journal of the Controlled Release Society. 2012;161:214-24.

19. Katz M, Fargnoli A, Gubara S, Fish K, Weber T, Bridges C, et al. Targeted Gene Delivery through the Respiratory System: Rationale for Intratracheal Gene Transfer. Journal of Cardiovascular Development and Disease. 2019;6:8. 
20. Sahu I, Haque AKMA, Weidensee B, Weinmann P, Kormann MSD. Recent Developments in mRNABased Protein Supplementation Therapy to Target Lung Diseases. Molecular Therapy. 2019;27:80323.

21. Birchall J. Pulmonary delivery of nucleic acids. Expert Opinion on Drug Delivery. 2007;4:575-8.

22. Alton EWFW, Armstrong DK, Ashby D, Bayfield KJ, Bilton D, Bloomfield E V, et al. Repeated nebulisation of non-viral CFTR gene therapy in patients with cystic fibrosis: a randomised, doubleblind, placebo-controlled, phase $2 b$ trial. The Lancet Respiratory medicine. 2015;3:684-91.

23. Beck SE, Laube BL, Barberena Cl, Fischer AC, Adams RJ, Chesnut K, et al. Deposition and expression of aerosolized rAAV vectors in the lungs of Rhesus macaques. Molecular therapy: the journal of the American Society of Gene Therapy. 2002;6:546-54.

24. Birchall JC, Kellaway IW, Gumbleton M. Physical stability and in-vitro gene expression efficiency of nebulised lipid-peptide-DNA complexes. International journal of pharmaceutics. 2000;197:221-31.

25. Johler SM, Rejman J, Guan S, Rosenecker J. Nebulisation of IVT mRNA Complexes for Intrapulmonary Administration. PloS one. 2015;10:e0137504.

26. Patel AK, Kaczmarek JC, Bose S, Kauffman KJ, Mir F, Heartlein MW, et al. Inhaled Nanoformulated mRNA Polyplexes for Protein Production in Lung Epithelium. Advanced materials (Deerfield Beach, Fla). $2019 ;:$ :e1805116.

27. Sandhaus RA, Turino G, Brantly ML, Campos M, Cross CE, Goodman K, et al. The Diagnosis and Management of Alpha-1 Antitrypsin Deficiency in the Adult. Chronic obstructive pulmonary diseases (Miami, Fla). 2016;3:668-82.

28. Brantly M, Nukiwa T, Crystal RG. Molecular basis of alpha-1-antitrypsin deficiency. The American journal of medicine. 1988;84:13-31.

29. de Serres F, Blanco I. Role of alpha-1 antitrypsin in human health and disease. Journal of internal medicine. 2014;276:311-35.

30. Santangelo S, Scarlata S, Poeta ML, Bialas AJ, Paone G, Incalzi RA. Alpha-1 Antitrypsin Deficiency: Current Perspective from Genetics to Diagnosis and Therapeutic Approaches. Current medicinal chemistry. 2017;24:65-90.

31. Stoller JK. Alpha-1 antitrypsin deficiency: An underrecognized, treatable cause of COPD. Cleveland Clinic journal of medicine. 2016;83:507-14.

32. Chapman KR, Chorostowska-Wynimko J, Koczulla AR, Ferrarotti I, McElvaney NG. Alpha 1 antitrypsin to treat lung disease in alpha 1 antitrypsin deficiency: recent developments and clinical implications. International journal of chronic obstructive pulmonary disease. 2018;13:419-32.

33. Janciauskiene SM, Bals R, Koczulla R, Vogelmeier C, Köhnlein T, Welte T. The discovery of a1antitrypsin and its role in health and disease. Respiratory medicine. 2011;105:1129-39.

34. de Loyola MB, Dos Reis TTA, de Oliveira GXLM, da Fonseca Palmeira J, Argañaraz GA, Argañaraz ER. Alpha-1-antitrypsin: A possible host protective factor against Covid-19. Reviews in medical virology. 2020;:e2157. 
35. Hoffmann M, Kleine-Weber H, Schroeder S, Krüger N, Herrler T, Erichsen S, et al. SARS-CoV-2 Cell Entry Depends on ACE2 and TMPRSS2 and Is Blocked by a Clinically Proven Protease Inhibitor. Cell. 2020;181:271-280.e8.

36. McElvaney OJ, McEvoy NL, McElvaney OF, Carroll TP, Murphy MP, Dunlea DM, et al. Characterization of the Inflammatory Response to Severe COVID-19 IIIness. American journal of respiratory and critical care medicine. 2020;202:812-21.

37. Strange C. Anti-Proteases and Alpha-1 Antitrypsin Augmentation Therapy. Respiratory care. 2018;63:690-8.

38. Wewers MD, Crystal RG. Alpha-1 antitrypsin augmentation therapy. COPD. 2013;10 Suppl 1:64-7.

39. Chiuchiolo MJ, Crystal RG. Gene Therapy for Alpha-1 Antitrypsin Deficiency Lung Disease. Annals of the American Thoracic Society. 2016;13 Suppl 4 Suppl 4:S352-69.

40. Connolly B, Isaacs C, Cheng L, Asrani KH, Subramanian RR. SERPINA1 mRNA as a Treatment for Alpha-1 Antitrypsin Deficiency. Journal of nucleic acids. 2018;2018:8247935.

41. Rejman J, Tavernier G, Bavarsad N, Demeester J, De Smedt SC. mRNA transfection of cervical carcinoma and mesenchymal stem cells mediated by cationic carriers. Journal of controlled release: official journal of the Controlled Release Society. 2010;147:385-91.

42. Choi YJ, Kim S, Choi Y, Nielsen TB, Yan J, Lu A, et al. SERPINB1-mediated checkpoint of inflammatory caspase activation. Nature immunology. 2019;20:276-87.

43. Dalby B, Cates S, Harris A, Ohki EC, Tilkins ML, Price PJ, et al. Advanced transfection with Lipofectamine 2000 reagent: primary neurons, siRNA, and high-throughput applications. Methods. 2004;33:95-103.

44. De Haes W, Rejman J, Pollard C, Merlin C, Vekemans M, Florence E, et al. Lipoplexes carrying mRNA encoding Gag protein modulate dendritic cells to stimulate HIV-specific immune responses. Nanomedicine (London, England). 2013;8:77-87.

45. Avci-Adali M, Behring A, Keller T, Krajewski S, Schlensak C, Wendel HP. Optimized conditions for successful transfection of human endothelial cells with in vitro synthesized and modified mRNA for induction of protein expression. Journal of biological engineering. 2014;8:8.

46. Rejman J, Oberle V, Zuhorn IS, Hoekstra D. Size-dependent internalization of particles via the pathways of clathrin- and caveolae-mediated endocytosis. The Biochemical journal. 2004;377 Pt 1:159-69.

47. Breunig M, Lungwitz U, Liebl R, Goepferich A. Breaking up the correlation between efficacy and toxicity for nonviral gene delivery. Proceedings of the National Academy of Sciences of the United States of America. 2007;104:14454-9.

48. Ernst N, Ulrichskötter S, Schmalix WA, Rädler J, Galneder R, Mayer E, et al. Interaction of liposomal and polycationic transfection complexes with pulmonary surfactant. The journal of gene medicine. 1999;1:331-40.

49. Densmore CL, Orson FM, Xu B, Kinsey BM, Waldrep JC, Hua P, et al. Aerosol delivery of robust polyethyleneimine-DNA complexes for gene therapy and genetic immunization. Molecular therapy: 
the journal of the American Society of Gene Therapy. 2000;1:180-8.

50. Abdulkarim A, Craig TJ. Alpha 1 Antitrypsin Mutation. Treasure Island (FL); 2020.

51. Koga H, Miyahara N, Fuchimoto Y, Ikeda G, Waseda K, Ono K, et al. Inhibition of neutrophil elastase attenuates airway hyperresponsiveness and inflammation in a mouse model of secondary allergen challenge: neutrophil elastase inhibition attenuates allergic airway responses. Respiratory research. 2013;14:8.

52. Mecham RP. Elastin in lung development and disease pathogenesis. Matrix biology: journal of the International Society for Matrix Biology. 2018;73:6-20.

\section{Figures}

A

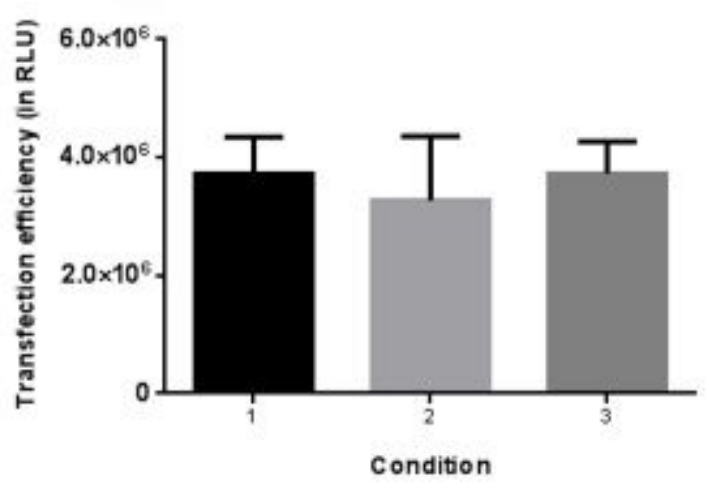

$\mathrm{C}$

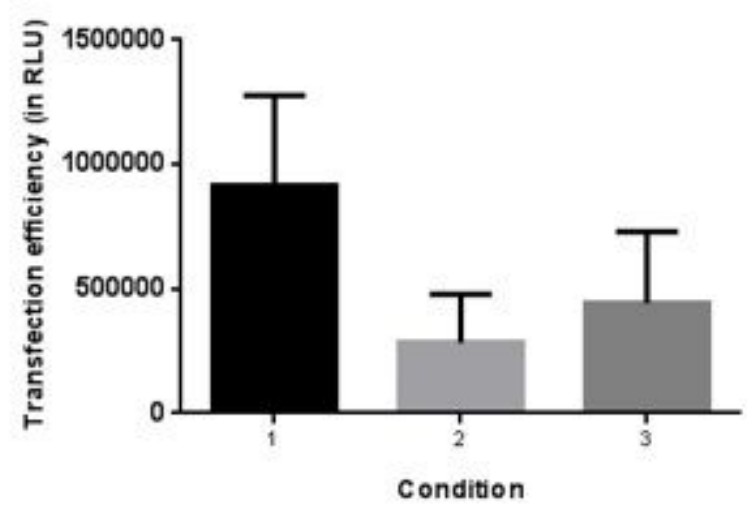

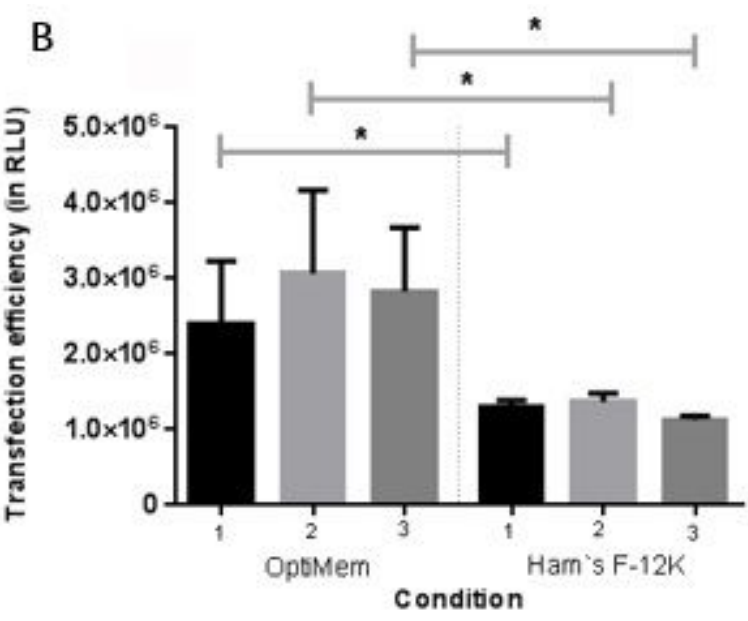

D

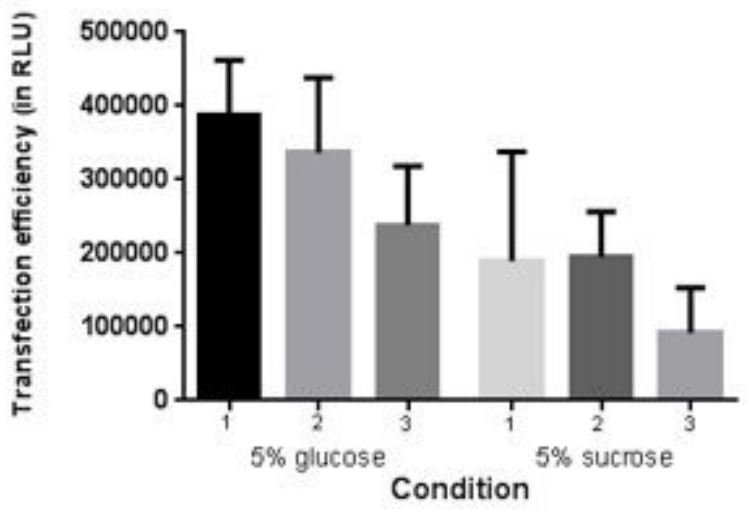

Figure 1

Optimization and characterization of the transfection process mediated by different IVTmRNA/Lipofectamine2000 complexes. (A) Transfection efficiency of complexes prepared at different Lipofectamine2000 to IVT-mRNA ratios in OptiMem. $2.4 \mu$ l (Condition 1), $3.6 \mu$ l (Condition 2) or $4.8 \mu \mathrm{l}$ (Condition 3) Lipofectamine2000 were mixed with $6 \mu$ IVT-mRNA encoding Metridia luciferase $(0.1 \mu \mathrm{g} /$ $\mu \mathrm{l}), \mathrm{n}=4$. (B) Transfection efficiency of complexes prepared in OptiMem or Ham's F-12K medium. $1.2 \mu \mathrm{l}$ (Condition 1), $2.4 \mu \mathrm{l}$ (Condition 2) or $3.6 \mu \mathrm{l}$ (Condition 3) Lipofectamine2000 were mixed respectively with 
$2 \mu \mathrm{l}$ (Condition 1), $4 \mu \mathrm{l}$ (Condition 2) or $6 \mu \mathrm{l}$ (Condition 3) of MetLuc-mRNA. n=4. (C) Transfection efficiency of MetLuc-mRNA lipoplexes prepared in $0.9 \%$ sodium chloride solution. (D) Transfection efficiency of complexes incubated in glucose and sucrose solution. The complexes were prepared in saline, then incubated with $16 \mathrm{HBE}$ cells in $5 \%$ glucose or $5 \%$ sucrose solution. For Figure $1 \mathrm{C}$ and Figure 1D, complexes were prepared by mixing $2.4 \mu \mathrm{l}$ (Condition 1), $3.6 \mu \mathrm{l}$ (Condition 2) or $4.8 \mu \mathrm{l}$ (Condition 3 ) Lipofectamine2000 with $6 \mu$ l MetLuc-mRNA; $n=6$. All complexes were incubated with $16 \mathrm{HBE}$ cells for $2 \mathrm{~h}$. The transfection efficiency was evaluated $24 \mathrm{~h}$ after adding complexes to the cells. The results are presented as relative light units $(\mathrm{RLU})$. A two-tailed student's t-test was used to determine significance (* $p<0.05$ and $* * p<0.005)$.

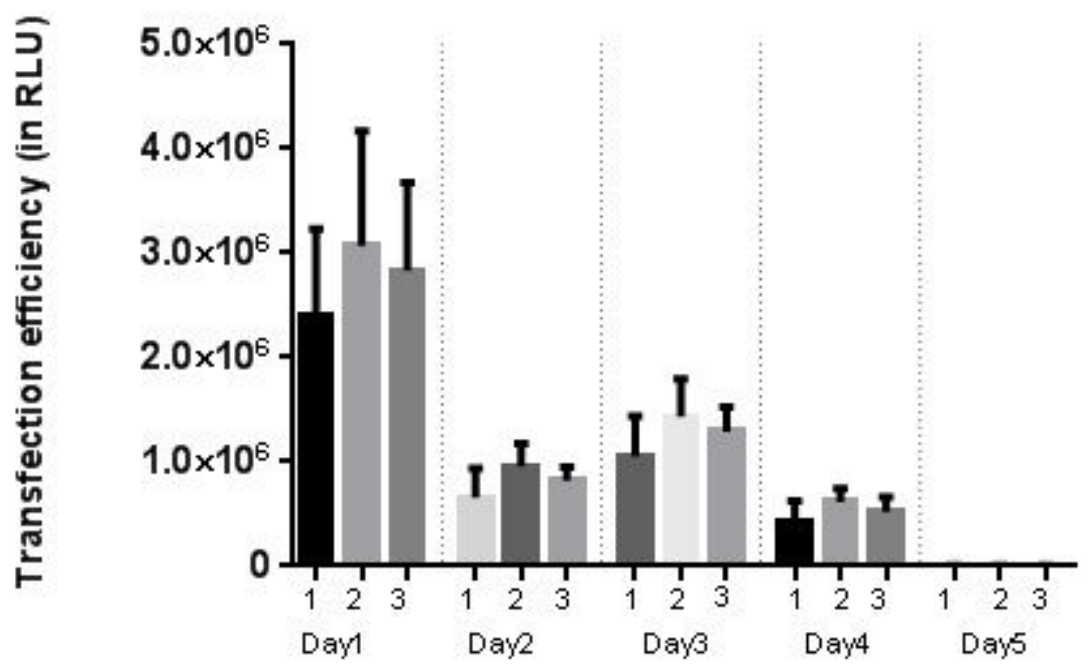

\section{Figure 2}

Time course of luciferase secretion after transfection with IVT-mRNA lipoplexes. Complexes were prepared by mixing $1.2 \mu \mathrm{l}$ (Condition 1), $2.4 \mu \mathrm{l}$ (Condition 2), or $3.6 \mu \mathrm{l}$ (Condition 3) of Lipofectamine2000 with $2 \mu \mathrm{l}$ (Condition 1), $4 \mu \mathrm{l}$ (Condition 2) or $6 \mu \mathrm{l}$ (Condition 3) of MetLuc-mRNA in OptiMem. 16HBE cells were incubated with the complexes for $2 \mathrm{~h}$. The luciferase activity was measured every $24 \mathrm{~h}$ till the relative light units measured with a luminometer dropped below 500 (back ground level). After each measurement the old medium was removed and the cells were supplied with fresh cell culture medium. The results are presented as relative light units (RLU); $n=4$. 
(A) OptiMem

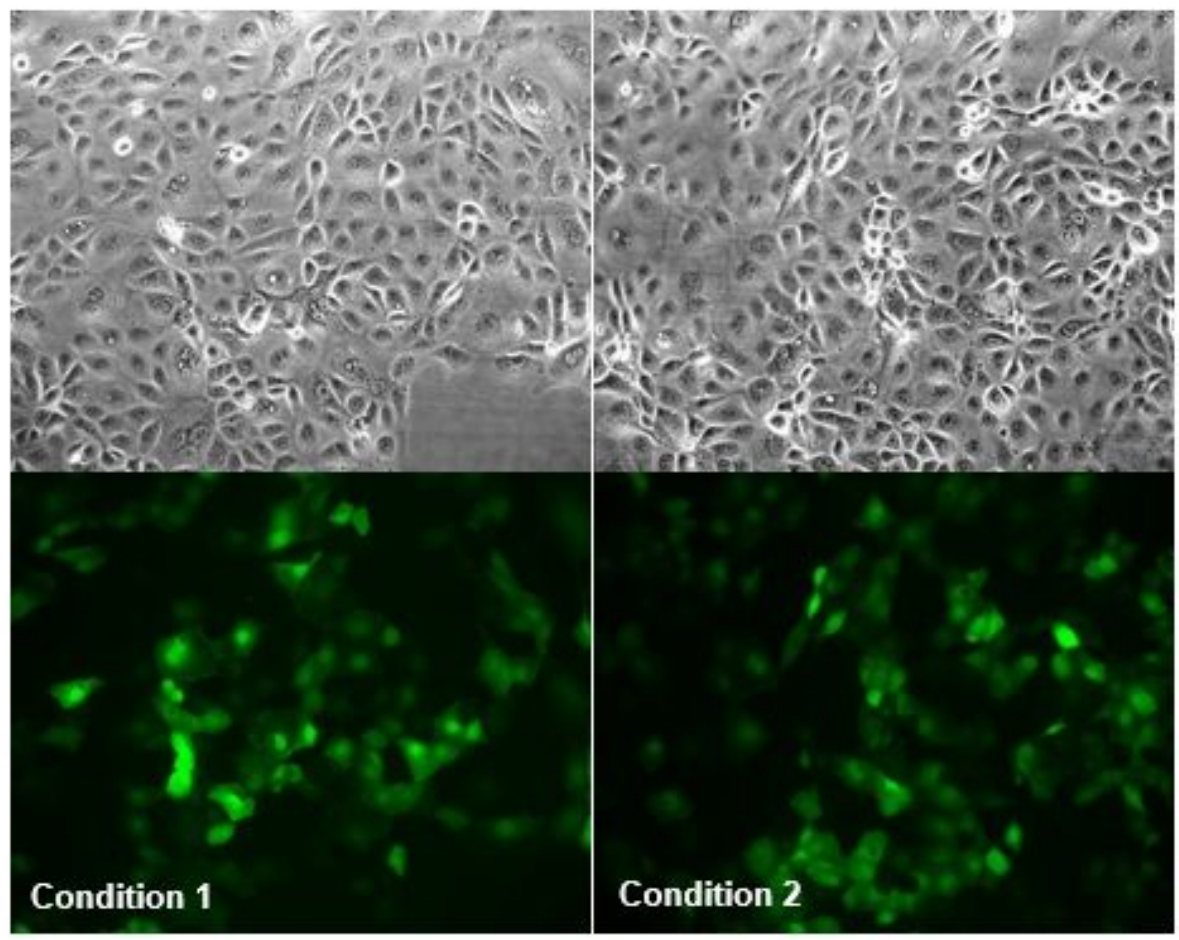

(B) Ham's F-12K medium

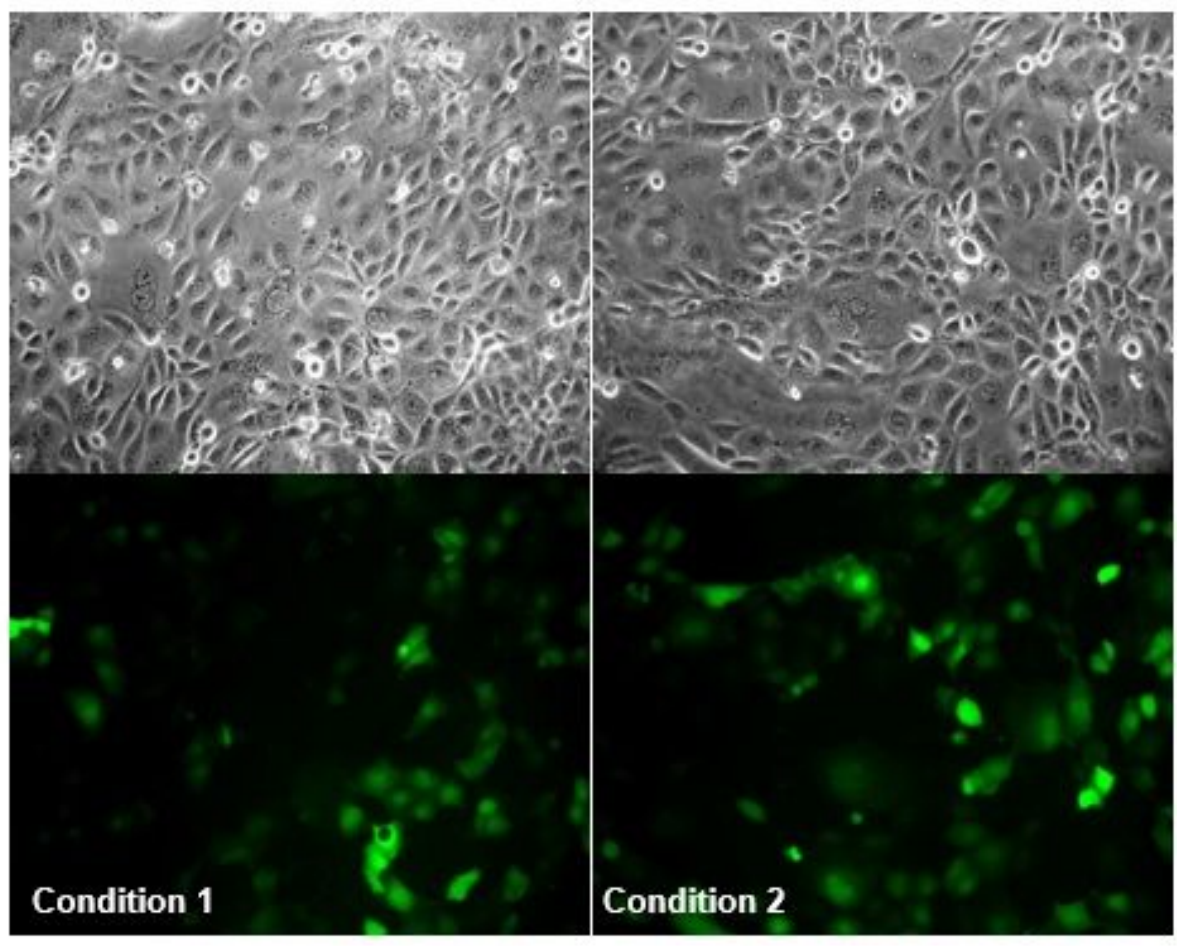

\section{Figure 3}

Transfection efficiency of GFP-mRNA on 16HBE cells. $2.4 \mu$ l (Condition 1) or $3.6 \mu$ l (Condition 2) Lipofectamine2000 was mixed respectively with $4 \mu$ l (Condition 1) or $6 \mu$ l (Condition 2) of IVT-mRNA encoding GFP $(0.1 \mu \mathrm{g} / \mu \mathrm{l})$. Complexes were prepared in OptiMem (A) or Ham's F-12K medium (B). 16HBE cells were incubated with GFP-mRNA/Lipofectamine2000 complexes for $2 \mathrm{~h}$. The pictures were taken 24 h after transfection with an Axiovert fluorescence microscope. 


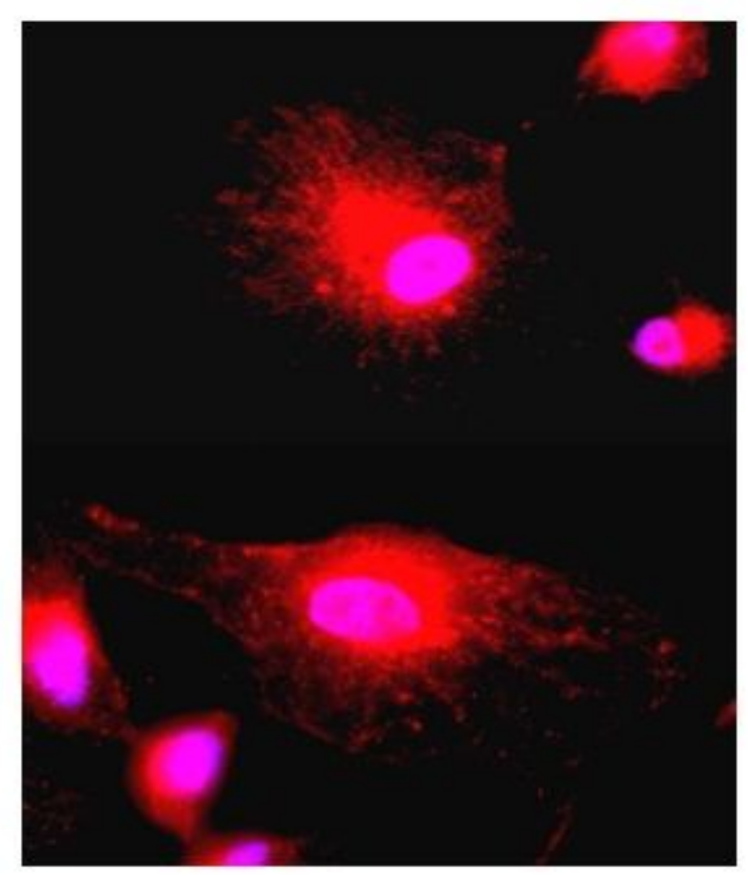

\section{Figure 4}

Intracellular A1AT visualized by immunofluorescence. $4.8 \mu \mathrm{l}$ Lipofectamine2000 was mixed with $6 \mu \mathrm{l}$ A1AT-mRNA $(0.1 \mu \mathrm{g} / \mu \mathrm{l})$ in OptiMem. $16 \mathrm{HBE}$ cells were incubated with the complexes for $2 \mathrm{~h}$. Brefeldin-A was used to prevent the protein secretion. Pictures were taken $24 \mathrm{~h}$ after transfection with an Axiovert fluorescence microscope. Red fluorescence represents A1AT, pink areas were cell nuclei stained by DAPI.

A
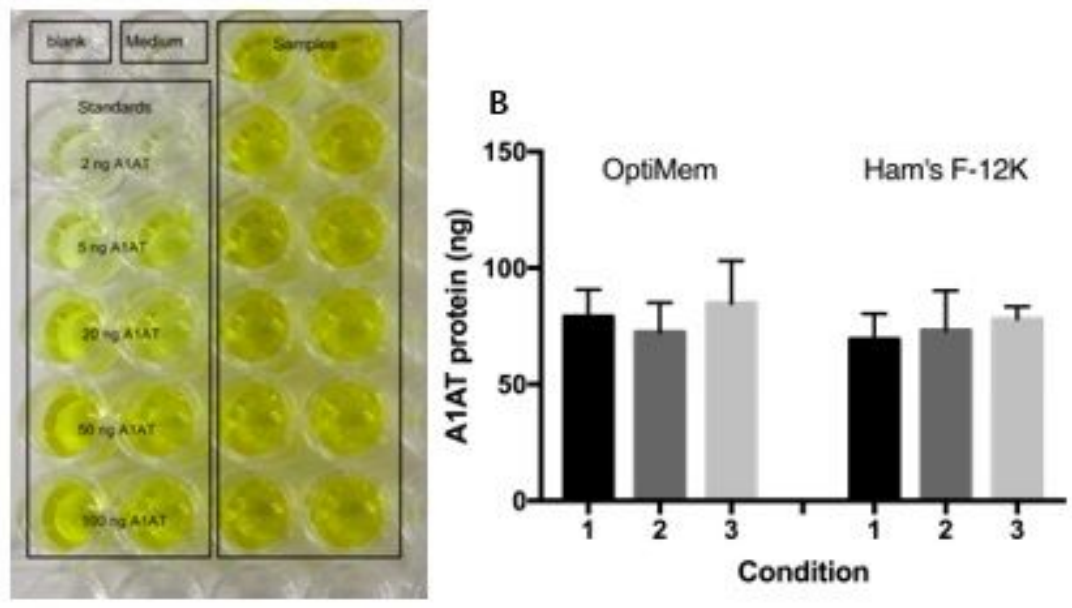

Figure 5

Transfection efficiency mediated by A1 AT-mRNA/Lipofectamine 2000 complexes. (A) A representative ELISA microplate. $24 \mathrm{~h}$ after transfection cell culture supernatants were collected and centrifuged at 3000 $\times \mathrm{g}$ for 10 minutes to remove debris. $50 \mu \mathrm{l}$ of each sample was pipetted into an ELISA plate. $2 \mathrm{ng}, 5 \mathrm{ng}, 20$ ng, $50 \mathrm{ng}$ and $100 \mathrm{ng}$ of A1AT-standards were used. (B) Detected amounts of secreted A1AT after transfection with IVT-mRNA/Lipofectamine2000 complexes. $2.4 \mu$ l (Condition 1), $3.6 \mu$ l(Condition 2) or 
$4.8 \mu \mathrm{l}$ (Condition 3) Lipofectamine2000 were mixed with $6 \mu \mathrm{l}$ A1AT-mRNA. OptiMem and Ham's F-12K medium were used to prepare complexes. $16 \mathrm{HBE}$ cells were incubated with the complexes for $2 \mathrm{~h}$. To calculate the amounts of produced and secreted A1AT a standard curve was employed, $n=4$.
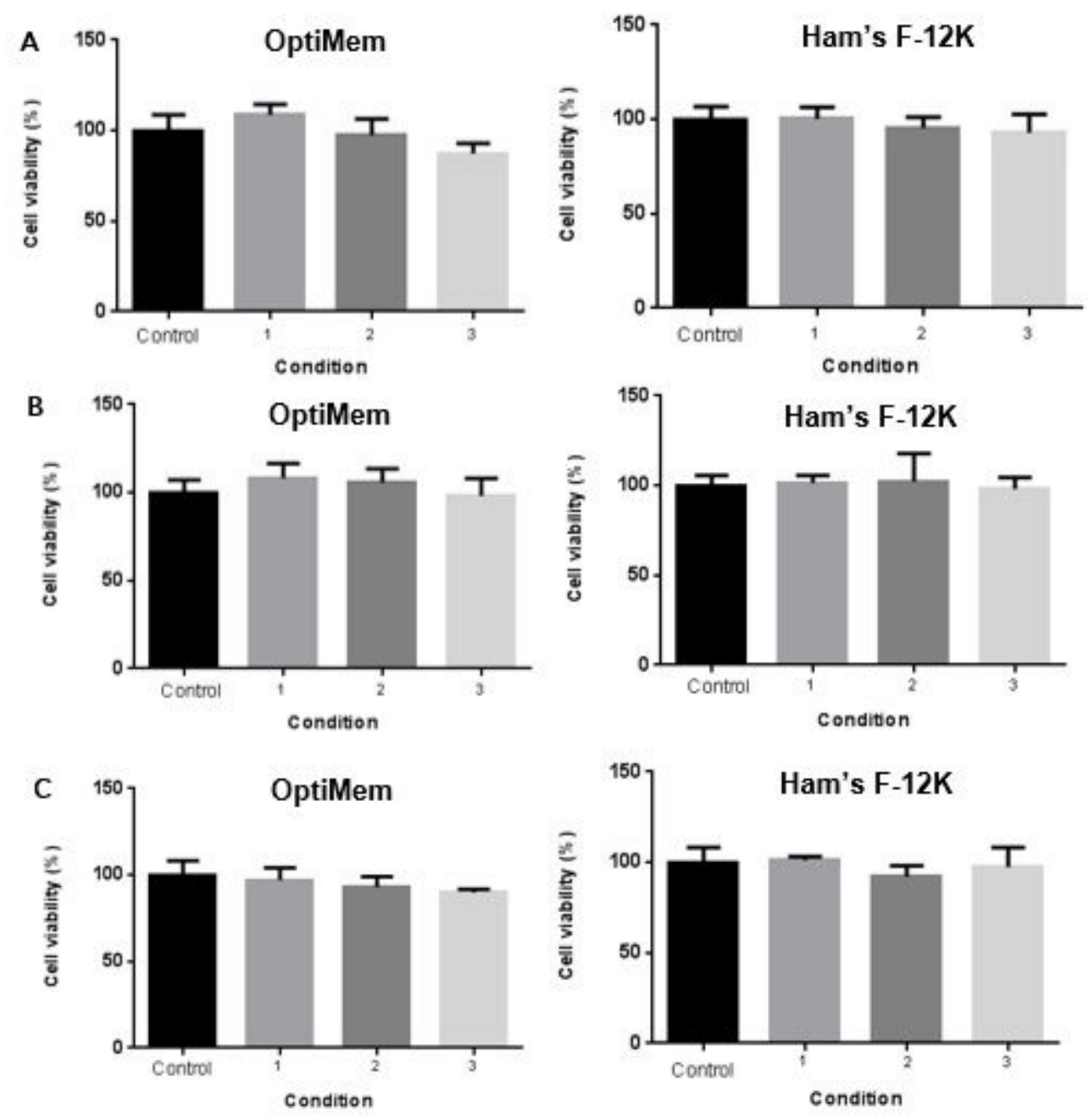

\section{Figure 6}

Cytotoxicity profile of IVT-mRNA/Lipofectamine2000 complexes towards $16 \mathrm{HBE}$ cells. The complexes were prepared in OptiMem or Ham's F-12K medium by mixing $1.2 \mu$ (Condition 1), $2.4 \mu$ (Condition 2) or $3.6 \mu \mathrm{l}$ (Condition 3) Lipofectamine2000 with $2 \mu \mathrm{l}$ (Condition 1), $4 \mu \mathrm{l}$ (Condition 2) and $6 \mu \mathrm{l}$ (Condition 3) MetLuc-mRNA (A) or GFP-mRNA (B) or A1AT-mRNA (C) at the concentration of $0.1 \mu \mathrm{g} / \mu \mathrm{l}$, respectively. The complexes were incubated with 16HBE cells for $2 \mathrm{~h}$. Cell viability was assayed $24 \mathrm{~h}$ after transfection via an MTT assay, untreated cells were used as a control $(100 \%), n=6$. 
A

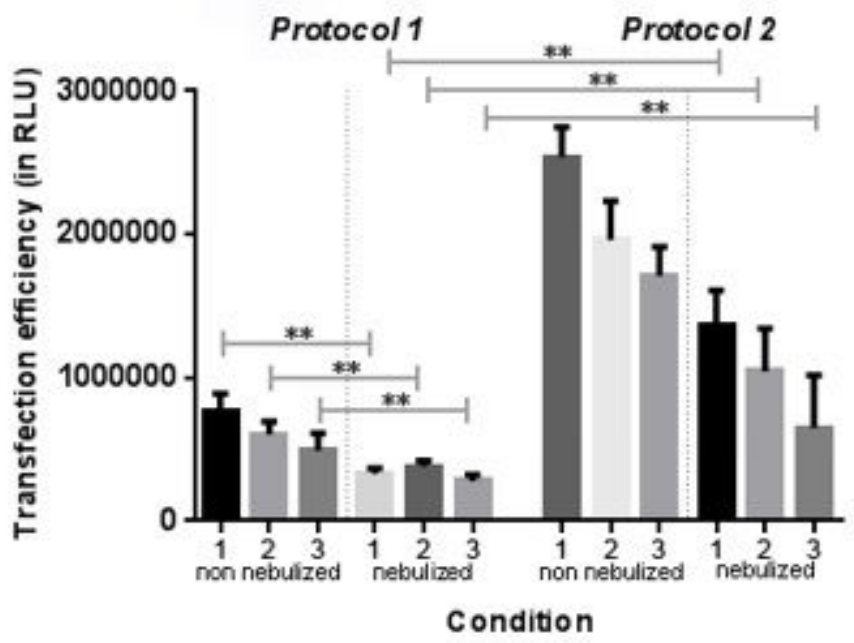

B

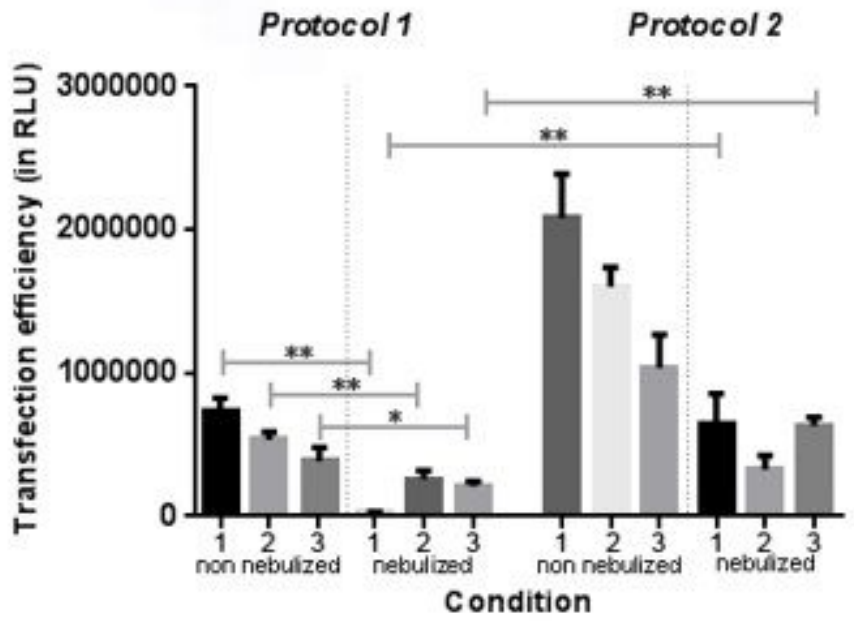

Figure 7

Transfection efficiency of MetLuc-mRNA/Lipofectamine2000 complexes before and after nebulization via different nebulization protocols. Lipoplexes were prepared in OptiMem (A) or Ham's F-12K medium (B). For protocol 1, $2.4 \mu \mathrm{l}$ (Condition 1), $3.6 \mu \mathrm{l}$ (Condition 2) and $4.8 \mu \mathrm{l}$ (Condition 3) Lipofectamine2000 was mixed with $6 \mu \mathrm{l}$ MetLuc-mRNA $(0.1 \mu \mathrm{g} / \mu \mathrm{l})$. After 10 minutes the samples were diluted in $3 \mathrm{ml}$ medium. For protocol 2, complexes were prepared with $7.2 \mu \mathrm{l}$ (Condition 1), $10.8 \mu \mathrm{l}$ (Condition 2) and 14.4 $\mu \mathrm{l}$ (Condition 3) Lipofectamine2000 mixed with $18 \mu \mathrm{l}$ MetLuc-mRNA $(0.1 \mu \mathrm{g} / \mu \mathrm{l})$. After 10 minutes the samples were diluted in $3 \mathrm{ml}$ medium. For both protocols, a fraction of the complexes was kept separately and used as a "non-nebulized" control. The rest of the solution was aerosolized for 5 minutes using a PARI Boy ${ }^{\circledR}$ jet-nebulizer and the collected part was used as "nebulized" formulation. Both the non-nebulized control complexes and the nebulized complexes were used to transfect 16HBE cells for 2 $\mathrm{h}$. The transfection efficiency was measured $24 \mathrm{~h}$ after transfection. The results are presented as relative light units (RLU), $n=5$. Significance was determined by a two-tailed unpaired t-test $\left({ }^{*} p<0.05\right.$ and ${ }^{*} p<$ 0.005). 
A

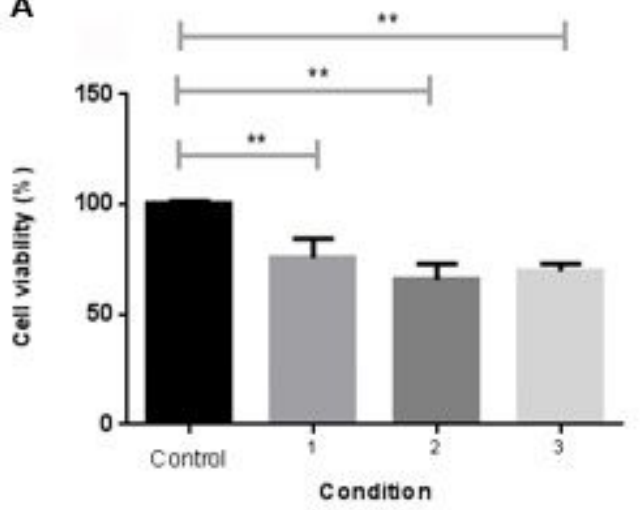

B

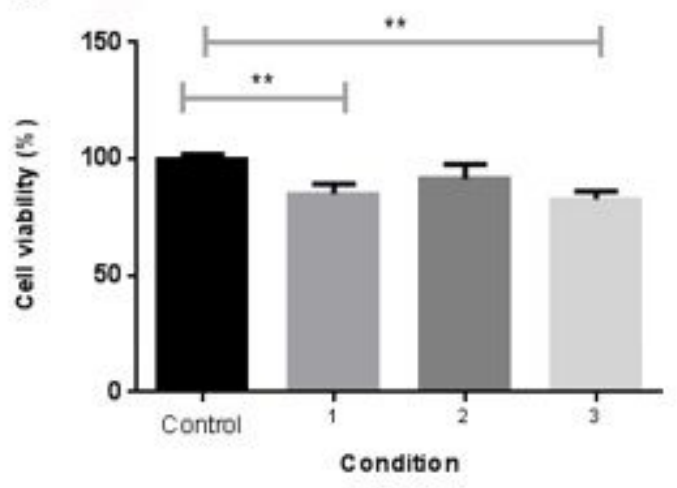

Figure 8

Cytotoxicity profile of nebulized MetLuc-mRNA/Lipofectamine2000 complexes towards 16HBE cells. Complexes were prepared in OptiMem (A) or Ham's F-12K medium (B) and incubated with 16HBE cells for $2 \mathrm{~h} .7 .2 \mu \mathrm{l}$ (Condition 1), $10.8 \mu \mathrm{l}$ (Condition 2) and $14.4 \mu \mathrm{l}$ (Condition 3) Lipofectamine2000 was mixed with $18 \mu \mathrm{l}$ MetLuc-mRNA. Cell viability was assayed $24 \mathrm{~h}$ after transfection. Untreated cells were used as $100 \%, n=6$. The results were analysed for the statistical significance with a student's t-test: ** $p<0.005$.

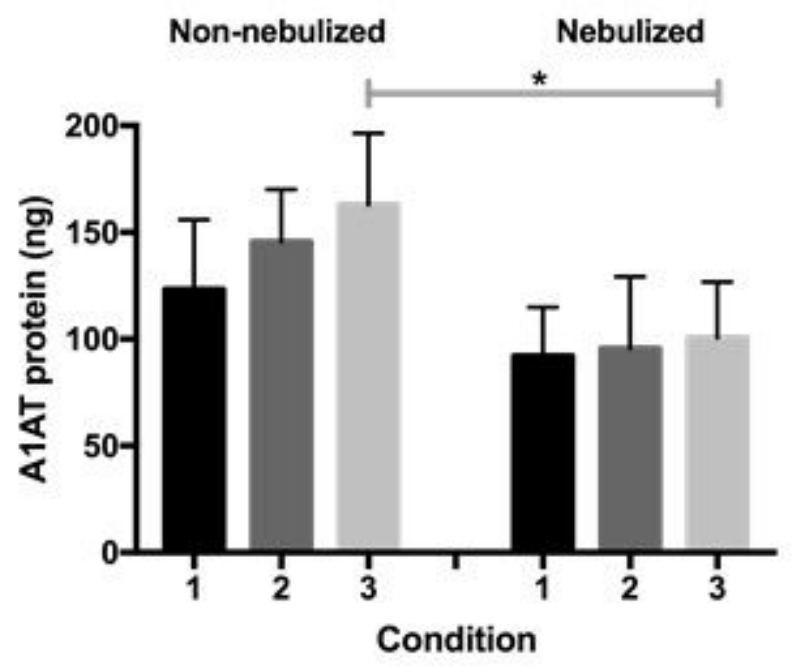

\section{Figure 9}

Nanograms of secreted A1AT after transfection with nebulized and non-nebulized A1ATmRNA/Lipofectamine2000 complexes. $7.2 \mu \mathrm{l}$ (Condition 1), $10.8 \mu \mathrm{l}$ (Condition 2) or $14.4 \mu \mathrm{l}$ (Condition 3) of Lipofectamine 2000 and $18 \mu \mathrm{l}$ of IVT-mRNA encoding A1AT $(0.1 \mu \mathrm{g} / \mu \mathrm{l})$ was mixed to prepare complexes. OptiMem was used as the transfection medium. A fraction of the complexes was kept separately and used as a "non-nebulized" control. The other fraction was aerosolized using a PARI Boy® jet-nebulizer and the "nebulized" formulation was collected. Both the non-nebulized complexes and the nebulized complexes were used to transfect $16 \mathrm{HBE}$ cells for $2 \mathrm{~h}$. The amount of secreted A1AT in supernatants was evaluated $24 \mathrm{~h}$ after transfection. A standard curve was employed for the calculation, $n=4$. Significance was determined by two-tailed unpaired t-test $(* p<0.05)$. 

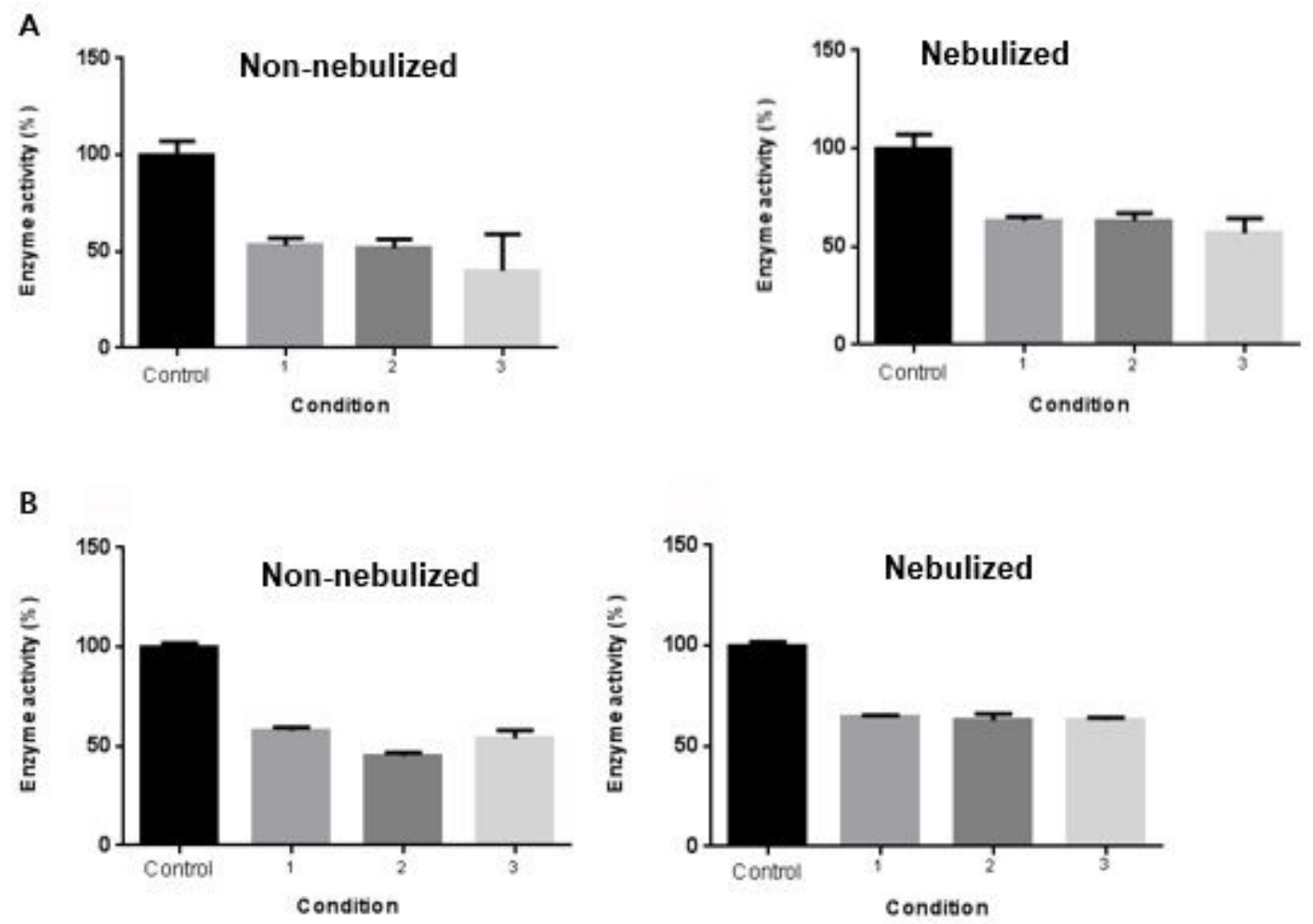

Figure 10

Functional assay of A1AT in supernatants of transfected cells. (A) Inhibition of trypsin activity by A1AT secreted from 16HBE cells transfected by non-nebulized or nebulized A1 AT-mRNA/Lipofectamine2000 complexes, $n=8$. (B) Inhibition of elastase activity by A1AT secreted from 16HBE cells transfected by nonnebulized or nebulized A1AT-mRNA lipoplexes, $n=4$. For both assays, $7.2 \mu$ (Condition 1), $10.8 \mu \mathrm{l}$ (Condition 2) or $14.4 \mu$ l (Condition 3) of Lipofectamine2000 and $18 \mu$ l of IVT-mRNA encoding A1AT (0.1 $\mu \mathrm{g} / \mu \mathrm{l})$ was mixed to prepare complexes. $16 \mathrm{HBE}$ cells were incubated with the A1AT-mRNA lipoplexes for $2 \mathrm{~h}$ and the medium was then replaced by a protein expression medium. The enzyme inhibition assay was performed $24 \mathrm{~h}$ after transfection. $50 \mu \mathrm{l}$ cell culture supernatants were added to the reaction buffer and the enzyme inhibition was assessed after the reaction. Samples did not treat with supernatants were used as positive controls and their absorbance were set as $100 \%$. 